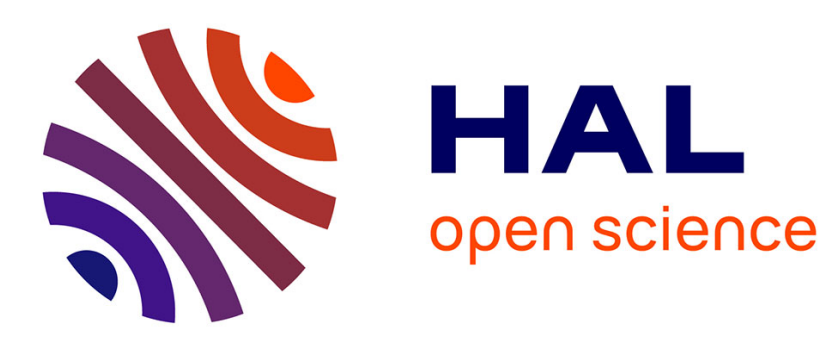

\title{
Gear impacts and idle gear noise: Experimental study and non-linear dynamic model
}

Jean-Luc Dion, Sylvie Le Moyne, Gaël Chevallier, Hamidou Sebbah

\section{To cite this version:}

Jean-Luc Dion, Sylvie Le Moyne, Gaël Chevallier, Hamidou Sebbah. Gear impacts and idle gear noise: Experimental study and non-linear dynamic model. Mechanical Systems and Signal Processing, 2009, 23 (8), pp.2608-2628. 10.1016/j.ymssp.2009.05.007 . hal-00708792

\section{HAL Id: hal-00708792 https://hal.science/hal-00708792}

Submitted on 20 Jun 2012

HAL is a multi-disciplinary open access archive for the deposit and dissemination of scientific research documents, whether they are published or not. The documents may come from teaching and research institutions in France or abroad, or from public or private research centers.
L'archive ouverte pluridisciplinaire HAL, est destinée au dépôt et à la diffusion de documents scientifiques de niveau recherche, publiés ou non, émanant des établissements d'enseignement et de recherche français ou étrangers, des laboratoires publics ou privés. 


\title{
Gear Impacts And Idle Gear Noise: Experi- mental Study And Non Linear Dynamic Model
}

\author{
Jean-Luc DION ${ }^{a, 1}$, Sylvie LE MOYNE ${ }^{\mathrm{b}}$, Gaël CHEVALLIER ${ }^{\mathrm{a}}$, \\ Hamidou SEBBAH ${ }^{\text {a }}$
}

${ }^{a}$ SUPMECA, 3 rue Fernand HAINAUT, F-93407 Saint OUEN, France

${ }^{\mathrm{b}}$ UPMC Univ Paris 6, CNRS-UMR 7190, IJLRDA, F-75005 Paris, France

\begin{abstract}
This paper develops an experimental and numerical study of dynamic phenomena involving gear impacts with one loose gear (non engaged gear pair) inside an automotive gearbox.

A dedicated test bench was designed for this study. Signal processing tools, based on the Order Tracking Method, were specially developed in order to clarify the underlying phenomena. A Particular attention was paid to the relationship between the drive shaft excitation and the energy and nature of impacts.

A topological model of contact is being proposed, based on a geometric description of solids in contact. The contact between gear meshes is defined using a Single Degree of Freedom, non linear, elastic and dissipative model. The chosen parameters of the model are not updated from measurements, but from the knowledge of the gear topology and tolerance class.

Simulations, compared with experimental results, confirm the accuracy of the model proposed.

Both model and experiments show, for particular excitation conditions, the emergence of repeated impacts on one side of the gear mesh.
\end{abstract}

Key words: Idle gear noise, hertzian contact, shock, backlash, non linear vibrations, signal processing 
Definition

Angular position of the main shaft

Angular position of the loose gear
Variable

$\theta_{M}$

$\theta_{L}$

\section{Definition}

Viscous coefficient introduced by lubricant between shaft and gear

Strutural damping of the L and M teeth in contact

Angular damping of the contact

Translational damping of the contact (along $\xi$-axis)

Momentum inertia of the loose gear

Strutural elasticity of the $\mathrm{L}$ and $\mathrm{M}$ teeth in contact

Angular elasticity of the contact

Translational elasticity of the contact (along $\xi$-axis)

Radius of the loose gear

Radius of the main shaft

Geometric defaults on the tooth

Exponent defined by the nature of the contact

Backlash

Pitch diameter on the loose gear

Pitch diameter on the main shaft
Parameters

C

$C_{L M}$

$C_{\theta}$

$C_{\xi}$

$I_{z z(k)}^{k}(P)=I_{L}$

$K_{L M}^{*}$

$K_{\theta}$

$K_{\xi}$

$r_{L}$

$r_{M}$

$\varepsilon$

$\alpha$

G

$\xi_{L}$

$\xi_{M}$ 
4 As the demand for acoustic comfort is constantly increasing, car 5 manufacturers are concerned by noise annoyance problems in vehicles, and especially by the annoyance generated by gearboxes. Among numerous gearboxes noises, idle gear noise is perceived as particularly disagreeable and often wrongly associated with an engine problem by consumers. This noise is generated by gear impacts which can appear either in driving conditions ("rattle" noise) or in neutral ("idle" noise or "neutral rattle" noise ). As neutral is the worst configuration, it is the focus of this paper.

The present paper presents an experimental and numerical study of the gear impact. The aim of the study is to define a simple and realistic model of contact able to describe the dynamic impacts between gears with invariant parameters for several frequencies, levels and types of excitations. To this end, the nonlinear Single Degree of Freedom (SDOF) gear pair model with backlash, which has often been investigated in the literature, has only included ${ }_{20}$ few parameters for the gear topology and tolerance class. The ${ }_{21}$ choice of the model to be developed was governed by a literature 22 study, but also by a preliminary experimental study.

${ }_{23}$ The test bench designed for this study is composed of an off-the${ }_{24}$ shelf simplified gear box (only one gear couple is kept). The choice ${ }_{25}$ of measurement and signal processing techniques was governed ${ }_{26}$ by the very transient character of the events being observed. This ${ }_{27}$ experimental part of the study particularly focuses on the deter28 mination of relationships between the excitation kinematics and 29 the nature and the energy content of the impact. Energy contents so are analyzed globally and also in terms of frequency distribution. 31 The model thus formulated endeavors to predict the dynamic 32 behaviour of a gear box by associating a limited number of nonз3 linear SDOF. After an analytical description of the model, para34 metric identification techniques are presented.

35 The only model parameters that are identified with experimental ${ }_{36}$ techniques are the dissipative coefficients. All other parameters 
of the model are determined in accordance with technical design data.

In the final section, before drawing our conclusions, numerical simulations and experimental measurements will be compared.

\section{Literature}

Most previous studies of such phenomena propose analytical models for the vibroacoustic behaviour of the entire mechanical system (gears, transmission chain). In [1], R.Singh et al. retain a Lumped Model, non-linear, and find analytical solutions, derived piecewise, section after section, from a linear analysis. In this particular case, the stiffness is described with functions which have non continuous derivatives. In [2], the authors improved the latter model by the introduction of friction. Moreover the authors derive analytical solutions based on the Harmonic Balance Method. Many investigations have been performed to define contact characteristics of simple or multi-mesh gear trains, taking into account friction phenomena and the influence of backlash. The first experiments focused on the detection and the analysis of nonlinear phenomena [3].

The instantaneous characteristics in the signals can be obtained from the ridges and skeletons of the Wavelet Transform [4]. Such non-linear systems can also be described with a Volterra Functional Series which generalise the Superposition Principle and allows Impulse Responses and Transfer Functions of various orders to be obtained [5]. Other Detection Methods are based on the speed variations, [6]; in this paper, the authors show that a low cost conventional tachometer is sufficient for measuring the induced speed variations due to backlash. They can also be predicted via simulation. For example, T. Tjahjowidodo et al., [4], uses a detailed multibody simulation to develop and test the effectiveness of the proposed detection approach.

The idle gear noise is chaotic [7]. The chaotic behaviour gets stronger with increasing backlash, see [8]. In [9], T. Tjahjowidodo 
et al., quantify the chaotic responses and correlate them to the parameters of the non-linear system, in particular the magnitude of the backlash.

A.Al-shyyab et al. ([10] and M. Ajmi et al. [11]) proposed models to introduce non-linearity in the contact elasticity. They also take into account the structural elasticity of gears. M. Ajmi et al. [10] considers a continuous non-linear model concentrated on contact lines in gears with a Finite Element global description. A.Alshyyab et al. [11] chose Lumped Models, non-linear with analytical solutions derived from decompositions in frequency domain. In a similar manner, J.P.Raclot et al. [12] built a combination of flexible bodies in contact with Spectral Methods for a wide excitation spectrum.

Various experimental studies, see for example ([13]), involve source location techniques by means of multiple Impulse Response Functions to detect sources of gearbox rattle using correlation between several excitations and several IRFs.

Other studies, of the complete gear box were performed taking into account the influence of manufacturing error on the rattle noise (see for example [14]). The degree of noise variability is assumed to be only induced by tolerances of geometric descriptions of gears. Mechanical models of solids are combined with acoustic models in a global statistical study. In The influence of the harmonic content of engine acyclism is analysed. As this is a main source of gear schoks, this work attempts to complement the work carried out by [15]. Models, such as the N.Barabanov et al. model [16], using Finite Element Methods are frequently employed for specific excitation sources: [17] introduces mechanical models for solids periodically excited by a static transmission error and incorporates acoustic models in the finite element method. Likewise, [18] conducted a study with several manufacturing errors (tooth spacing - pitch, eccentricities, misaligned gears ) and variation in excitations using the model described in [10].

The vibroacoustic behaviour of the gear box is generally assumed to be linear and described by transfer functions following propa- 
gation paths for solid transmission of vibration and vibroacoustic coupling with fluid propagation (atmosphere) for acoustic transmission ([19] [17]).

The only mechanical elements which cannot be described by linear models are bearings ([20], [21], [22], [23]) and gears in contact.

\section{Test Bench}

\subsection{Gear Box}

The test bench must show impacts induced by backlash between two gears. Thus, all other sources of uncontrolled vibrations have to be suppressed.

The solution adopted was to obtain an off-the-shelf gearbox and modify it in order to keep only one gear couple ( $4^{\text {th }}$ gear). As a result of the gaps due to the removal of gears and the entire command system, crossbars were added.

Principal gear data are the following:

- $4^{\text {th }}$ helical gear on the main shaft:

- pitch diameter: $57 \mathrm{~mm}$

- number of teeth: 28

- face width: $20 \mathrm{~mm}$

- helix angle: $30^{\circ}$

- $4^{\text {th }}$ loose helical gear:

- pitch diameter: $74 \mathrm{~mm}$

- number of teeth: 37

- face width: $20 \mathrm{~mm}$

- helix angle: $30^{\circ}$

- Contact ratio: 2.9

- individual pitch error : between $3 \mu \mathrm{m}$ and $15 \mu \mathrm{m}$ 
The translational oscillations of an electrodynamics shaker rod are transformed into angular oscillations of the main shaft through two perpendicular transmission beams (Fig .1 and Fig .2). The motion obtained is pure angular oscillations with an average angular speed equal to zero. The authors chose to carry out the experiment in this way in order to reproduce a gearbox in neutral. Transmission beam dimensions were calculated in order to respect the following conditions:

- The circular trajectory of the joint between the two transmission beams (point A) should not damage the shaker.

- The eigen frequencies of the excitation system should not perturb measurements.

The rigid transmission beam, between the flexible beam and the axe of the main shaft, is $165 \mathrm{~mm}$ long.

The excitation reproduces actual engine torque oscillations which are sources of the noise and vibration under study: sinusoidal excitation from $30 \mathrm{~Hz}$ to $60 \mathrm{~Hz}$ with a maximal oscillation magnitude of $2000 \mathrm{rad} / \mathrm{s}^{2}$.

\subsection{Measurement Setup}

The excitation is controlled by a piezoelectric accelerometer fixed on the output of the shaker. In order to verify the non distortion of the signal transmitted to the main shaft of the gearbox, a second accelerometer is fixed at the end of the main shaft.

A rigid support is inserted in the loose gear under study, at 46 $\mathrm{mm}$ from the axe. This support is used for the fixation of a piezoelectric accelerometer.

A hole was made in the gearbox house for accessibility and fixation of sensors (Fig .3 and Fig .4). The natural eigen frequency of the support was calculated greater than $3200 \mathrm{~Hz}$. 


\subsection{Signal Processing And Analysis Method}

- Instantaneous temporal signals

- Periodgrams representing the magnitude of the loose gear acceleration, according to the period $N=t . F_{e x}$ where $t$ is time and $F_{e x}$ the excitation frequency

- Three dimensional spectral representations of loose gear acceleration magnitude versus frequency (or tracking order) and excitation frequency.

Measures are converted from translation motion to angular motion in order to respect the kinematical properties of the system (Fig .3).

The system is excited by a sine wave with a variable frequency, the observed responses are then periodic but not harmonic. Experimental results are thus to be normalized to the excitation frequency. A re-sampling technique based on FIR filter algorithm is implemented to avoid signal distorsion. 
One can first observe instantaneous time signals (Fig .5). Different types of behaviour appear, depending of the excitation level:

- for low excitation levels, no impact appears between the teeth of the gears,

- as the excitation increases, an impact occurs only on one side $(\mathrm{F}+)$ of the tooth. After the impact, the behaviour of the tooth leads to free vibrations (Fig .5c),

- for greater excitation, impacts occur on both sides of the tooth (F+ and F-). The impact level on F+ is greater and free vibrations are observed only for this impact (Fig .5d),

- when the level of excitation increases, two impacts are observable in a very short time (less than 1ms): two pairs of teeth are in contact at the same time (Fig .5h),

- for the greatest excitation the impact on F- becomes stronger than the one on F+ (Fig .5g).

Those behaviours and their evolution were observed in the entire range of the excitation frequency $([30 \mathrm{~Hz} 60 \mathrm{~Hz}])$.

It is particularly interesting to observe that impacts appear several times on the same side F+ before changing the side F-. Indeed, the first impact is not strong enough to push the tooth up to the other side. Two or three impacts then occur before changing the side of impact. This phenomenon appears more clearly on periodgrams (Fig .6).

Acceleration signals of the loose gear show areas with a constant acceleration near zero (Fig .7 right). For these short sections, the velocity decreases slowly (Fig .7 left): the loose gear is in free motion with a small damping. During those sections of "free motion", the decay of the velocity is proportional to the velocity: this energy dissipation can then be described with a classical viscous damping as an angular dashpot. This behaviour is due to the lubricant between the second shaft and the loose gear.

The analysis of the relative displacement on the pitch diameter 
251 The excitation is controlled thanks to an accelerometer placed on

252 the electrodynamics shaker head.

allows one to estimate the backlash between gears. When the level of excitation increases, this free motion gap presents an apparent increase (from $40 \mu \mathrm{m}$ to $80 \mu \mathrm{m}$ ): in fact, for the highest level, some parts of the mechanism can not be assumed to be rigid bodies, flexible behaviour has to be introduced. For example, a $1000 \mathrm{~N}$ force on the driving arm induces a deformation of $10 \mu \mathrm{m}$. The actual backlash is in fact $80 \mu \mathrm{m}$.

\subsection{Frequency Analysis}

Spectral analysis is represented in the frequency domain or with the Tracking Order Method. The three dimensional representations in Fig .8 show the evolution of the spectral signature of the teeth impacts in accordance with the excitation level for two excitation frequencies: $30 \mathrm{~Hz}$ and $60 \mathrm{~Hz}$. For both frequencies a threshold of excitation shows a break-even point from which the impact spectrum extended strongly from $500 \mathrm{~Hz}$ to more than $5000 \mathrm{~Hz}$. In all the experiments, the signal level strongly decreases around $3200 \mathrm{~Hz}$ : this is due to the sensor support plate on which measurements are performed, which plays the rule of dynamic absorber tuned at 3200Hz (Fig .8).

\subsection{Parametric Analysis}

With the aim of showing the influence of acceleration, velocity and displacement levels, three classes of experiments have been conducted with the excitation frequency between $30 \mathrm{~Hz}$ and 60 $\mathrm{Hz}$ :

- at a constant displacement magnitude,

- at a constant velocity magnitude,

- at a constant acceleration magnitude, 
These experiments were performed with several levels of excitation.

The figure .5 represents periodgrams according to the excitation frequency for each of the three classes of measurements.

Periodgrams with a constant magnitude of the excitation acceleration is the most invariant with excitation frequency (in term of energetic level of impacts). According to a simple linear approach, forces can be described in terms of acceleration. So the acceleration of the loose gear depends on the impact force and consequently on the excitation level of the main shaft.

The number of impacts on a given side strongly depends on the displacement level induced by the angular oscillations of the main shaft: for a given main shaft displacement magnitude, the energetic level of impacts increases with the excitation frequency, but the number of impacts keep the same.

\section{Model}

\subsection{Global Description}

The model proposed in the present paper is based on a non linear Single angular Degree Of Freedom (Fig .8) which can relate the main shaft behaviour to the loose gear in terms of force, torque, acceleration, speed and position in translation and rotation. The non linear approach is obvious: for an excitation composed of a single frequency, the dynamic response can be broken down into several frequencies over ten times the excitation frequency. The very first excitation is introduced by the behaviour of the main shaft. The neutral gear dynamic rattle appears with impacts between loose gears and the main shaft. The only possible transmission path for vibrations is the shaft, which is supposed to have a linear behaviour. Moreover, the main non linear behaviour is concentrated between the main shaft and the loose gear.

For this paper several models were considered in order to pro- 
pose the most appropriate one for the study. The very first tested models are lumped models described by [15] and [10]. These models are made with specific non linearity of elasticity and damping with the objective to performing analytical solutions section after section. The dynamic description of the contact and impacts is performed as a succession of sections (based on periodic solutions). In such models, the dynamic response between two temporal sections (large and discontinuous evolution of the stiffness for example) does not take into account the gradual evolution of the stiffness between the two states. Although, several studies ([24], [25]) had established that the dynamic response of solids in contact depends strongly on the progression of the stiffness function and more precisely on the geometric defaults (shape and micro geometry in terms of roughness). Simulations performed with these models overestimate the number and the levels of impacts and underestimate the duration of each impact (still using parametric identification obtained by updating the models with measurements). For these reasons this kind of Lumped Model was abandoned.

Other tested techniques ([13]) consist in building the solution in the frequency domain with a semi analytic method. This approach needs a specific analytical description of elasticity and damping (such as polynomial decomposition) and a large number of terms if realistic simulations are required. More over, this method could not describe an important phenomenon experimentally observed: several impacts occur on the same side of a tooth before changing sides. For these reasons this kind of method was not retained either.

Models based on Finite Element Method ([26]) are very heavy models in terms of computing time and memory. Moreover, it remains difficult to describe the complete geometry with specific defaults as roughness, which are important parameters in the dynamic of the shocks. However, this technique could be successfully used with the aim of identifying the structural stiffness of solids. For dynamic excitations this kind of model could not be used with reasonable computation time except for specific kinds 
of excitation $([26])$. In the present study, the roughness had to be taken into account and the excitation is not supposed to be known. This is the reason why this method has not been developed in this paper.

The proposed Lumped Model can be considered as a prolongation of classical Single Degree Of Freedom with non linear stiffness and damping. Models of stiffness and damping were chosen with the aim of taking into account the backlash, the geometric default of tooth (roughness) and the nature of the contact.

The elementary model for rotation on the $\mathrm{z}$ axis is defined by:

$$
I_{L} \ddot{\theta}_{L}+K_{\theta}\left(\theta_{M}, \theta_{L}\right)+C_{\theta}\left(\dot{\theta}_{M}, \dot{\theta}_{L}, \theta_{M}, \theta_{L}\right)+C \dot{\theta}_{L}=B
$$

with:

- $B$ : external torque

- $C$ : viscous coefficient for dissipative behaviour introduced by lubricant between the loose gear and the shaft.

The transmission error $\xi$ on the curvilinear axis for translation displacement (on pitch diameters) is defined by:

$$
\xi=\xi_{L}-\xi_{M}=r_{L} \theta_{L}-r_{M} \theta_{M}
$$

where $r_{L}$ and $r_{M}$ are respectively the pitch radius of the loose gear and the main gear.

Impacts are conditioned by $\xi$ along the pitch diameter, although the nonlinear dynamic equation for the elementary model is written for the angular variable.

$K_{\theta}\left(\theta_{M}, \theta_{L}\right)$ the angular elasticity of the contact and $C_{\theta}\left(\theta_{M}, \theta_{L}, \dot{\theta}_{M}, \dot{\theta}_{L}\right)$ the angular dissipation of the contact are simply and respectively linked to $K_{\xi}\left(\theta_{M}, \theta_{L}\right)$ and $C_{\xi}\left(\theta_{M}, \theta_{L}, \dot{\theta}_{M}, \dot{\theta}_{L}\right)$ the same function projected on the axis :

$$
\begin{aligned}
& K_{\theta}\left(\theta_{M}, \theta_{L}\right)=r_{L} K_{\xi}\left(\xi_{M}, \xi_{L}\right) \\
& C_{\theta}\left(\theta_{M}, \theta_{L}, \dot{\theta}_{M}, \dot{\theta}_{L}\right)=r_{L} C_{\xi}\left(\xi_{M}, \xi_{L}, \dot{\xi}_{M}, \dot{\xi}_{L}\right)
\end{aligned}
$$


Five different cases are considered, depending on transmission error value compared to geometric manufacturing errors and backlash (see figure .11).

The explicit expression of the contact elasticity $K_{\xi}\left(\xi_{M}, \xi_{L}\right)$ is:

- when the gears are in contact on side $\mathrm{F}+: \forall \xi \leq-\varepsilon$

$$
K_{\xi}=K_{L M}^{*}\left(\xi_{L}-\xi_{M}\right)\left|\frac{\xi_{L}-\xi_{M}}{G}\right|^{\alpha-1}
$$

- when the gears are near the contact on side $\mathrm{F}+: \forall-\varepsilon \leq \xi \leq 0$

$$
\begin{aligned}
& K_{\xi}=\frac{K_{L M}^{*}}{2}\left(1-\left(\frac{\varepsilon}{2}+\xi_{L}-\xi_{M}\right) \sin \left(\frac{\pi}{\varepsilon}\right)\right) \\
& \left(\xi_{L}-\xi_{M}\right)\left|\frac{\xi_{L}-\xi_{M}}{G}\right|^{\alpha-1}
\end{aligned}
$$

- when the gears are separated : $\forall 0 \leq \xi \leq G$

$$
K_{\xi}=0
$$

- when the gears are near the contact on side F- : $\forall G \leq \xi \leq G+\varepsilon$

$$
\begin{aligned}
& K_{\xi}=\frac{K_{L M}^{*}}{2}\left(1-\left(\frac{\varepsilon}{2}-\left(\xi_{L}-\xi_{M}-G\right)\right) \sin \left(\frac{\pi}{\varepsilon}\right)\right) \\
& \left(\xi_{L}-\xi_{M}-G\right)\left|\frac{\xi_{L}-\xi_{M}}{G}-1\right|^{\alpha-1}
\end{aligned}
$$

- when the gears are in contact on side F- : $\forall G+\varepsilon \leq \xi$

$$
K_{\xi}=K_{L M}^{*}\left(\xi_{L}-\xi_{M}-G\right)\left|\frac{\xi_{L}-\xi_{M}}{G}-1\right|^{\alpha-1}
$$

with :

- $K_{L M}^{*}$ the equivalent static stiffness of contact between the teeth $\mathrm{L}$ and $\mathrm{M}([24])$

- $\alpha$ the contact-type coefficient (e.g. sphere to plane, cylinder to cylinder ) $([27])$ (see figure .10

- $\epsilon$ the size of manufacturing errors on the tooth ( e.g. shape defects and micro-geometric defaults) ([25]) 
- $G$ the backlash ([28]) on the pitch diameter.

373 The equation (6 and 8) ensure the continuity of the function $K_{\xi}$

374 and its first derivatives.

The dissipative coefficient of the contact is defined with the same existing conditions as for the elasticity function.

This kind of normal contact model is used in several applications: for particular applications such as the dynamic behaviour of the compressor valve contacts or non lubricated gears, a friction dissipative term in the dissipative function had to be introduced ([29]).

The explicit expression for the dissipative coefficient $C_{\xi}\left(\xi_{M}, \xi_{L}, \dot{\xi}_{L}, \dot{\xi}_{M}\right)$ is:

- $\xi \leq-\varepsilon$

$C_{\xi}=C_{L M}\left(\dot{\xi}_{L}-\dot{\xi}_{M}\right)$

- $-\varepsilon \leq \xi \leq 0$

$C_{\xi}=\frac{C_{L M}}{2}\left(1-\left(\frac{\varepsilon}{2}+\xi_{L}-\xi_{M}\right) \sin \left(\frac{\pi}{\varepsilon}\right)\right)\left(\dot{\xi}_{L}-\dot{\xi}_{M}\right)$

- $0 \leq \xi \leq G$

$C_{\xi}=0$

- $G \leq \xi \leq G+\varepsilon$

$C_{\xi}=\frac{C_{L M}}{2}\left(1-\left(\frac{\varepsilon}{2}-\left(\xi_{L}-\xi_{M}-G\right)\right) \sin \left(\frac{\pi}{\varepsilon}\right)\right)\left(\dot{\xi}_{L}-\dot{\xi}_{M}\right)$

- $G+\varepsilon \leq \xi$ $C_{\xi}=C_{L M}\left(\dot{\xi}_{L}-\dot{\xi}_{M}\right)$

Where $C_{L M}$ denotes the associated damping of contact between the teeth $L$ and $M([29])$

\section{Model Characterization}

\subsection{Aims And Methods}

The aim of the proposed model is to simulate the source of dynamic excitation in gear boxes.

The model proposed in the present paper is deterministic and preserves stationary properties. Each parameter is invariant and 
independent of the excitation level and the frequency.

All parameters, except for dissipative behaviour, were identified without dynamic measurements. Most of them had been produced by Renault SA. Some of them, such as $K_{L M}^{*}, K_{\theta}$ and $\alpha$ were determined by using classical engineering gears methods ([28]). The choice of the model and its parameters had been strongly influenced by the possibility to identify the parameters with a greater degree of accuracy.

Each parameter is determined by a simple analytic model based on the design of gear. But they can also be identified by a single dynamic measure on the studied test bench excited with harmonic signal.

For each degree of freedom, 9 parameters had to be identified for the model:

- geometric parameters: $I_{L}, r_{L}, r_{M}$

- elastic parameters: $K_{L M}, \alpha, \epsilon, G$

- dissipative parameters: $C_{L M}, C$

These parameters are presented and explained in greater detail in paragraphs 7.2 to 7.4. Numerical values for each parameter are given in the case of the studied gear box. Corresponding simulations are presented in paragraph 8 , and compared with the experiments.

\subsection{Geometric parameters}

- $I_{L}$ : Moment of Inertia for the loose gear. Normally, this parameter is obtained numerically from the geometrical model and the density of the material. $\left(I_{L}=0.32\left(10^{-3}\right) \mathrm{kg} \cdot \mathrm{m}^{2}\right)$

- $r_{L}$ and $r_{M}$ : are respectively the pitch radius of the loose gear and the main gear $\left(r_{L}=37 \mathrm{~mm}\right.$ and $\left.r_{M}=28.25 \mathrm{~mm}\right)$

\subsection{Elasticity}

- $K_{L M}$ : the equivalent elasticity between the $L$ and $M$ teeth in contact. This can be obtained by a numerical identification 
with a Finite Element study of teeth in contact or more easily by the retained method defined by Palmgren ([24]). To avoid coupling with $\alpha$ and $G$ parameters and unit incompatibility, the parametric identification is performed on $K_{L M}^{*}=K_{L M} \cdot G^{(\alpha-1)}$. This method reveals a non-dimensional variable $\xi *=\xi / G$ and independent parameters $K_{L M}^{*}, \alpha, G .\left(K_{L M}^{*}=3\left(10^{6}\right) \mathrm{N} . \mathrm{m}^{-1}\right.$; $\left.K_{L M}=1.03 .\left(10^{8}\right) \mathrm{N} \cdot \mathrm{m}^{-4 / 3}\right)$.

- $\alpha$ : This coefficient is defined according to the type of contact ([27]): a simple line contact leads to $\alpha=10 / 9$, a single point leads to $\alpha=3 / 2$. In fact, for spur or helical gears the actual contact is neither linear nor punctual. This parameter had then to be identified between these two cases and was used to minimize the discrepancy between experimental measures and numerical simulations (Fig .10). ( $\alpha=4 / 3)$. Generaly speaking gear manufacturing requires that gear teeth are shaped to ensure a contact area limited to the central part of the tooth [28].

- $\epsilon$ : the size of manufacturing errors on the teeth (shape defects and micro-manufacturing errors) ([25]). This parameter transforms the point discontinuity into a continuous curve over an infinitesimal displacement interval thus the instantaneous stiffness increases from 0 to the equivalent solid stiffness $K_{L M}$ over the deformation interval $\epsilon$ of manufacturing errors $\left(\epsilon=1.10^{-6}\right.$ $\mathrm{m})$.

- $G$ : the backlash ([28]) on the pitch perimeter (projected onto the $\xi$ axis). This parameter is the main cause of idle gear noise. As this parameter is well known and statistically verified during the manufacturing process it cannot be excluded from consideration for technological reasons such as assembly or operating constraints. $(G=0.025 \mathrm{~mm})$

The complete elastic function is defined by 6 parameters $\left(r_{L}, r_{M}\right.$, $\left.K_{L M}, \alpha, \epsilon, G\right)$ and 2 variables $\xi_{L}$ and $\xi_{M}$.

$K_{\xi}\left(\theta_{M}, \theta_{L}\right)$ is exhaustively defined by 4 parameters $\left(K_{L M}, \alpha, \epsilon\right.$, $G)$. (Fig .11) 
$C_{L M}$ is the associated damping of the $L$ and $M$ teeth in contact ([24]).To avoid coupling with $K_{L M}, I_{L}, \alpha, G$ and $\mathrm{rL}$ parameters, the parametric identification is obtained from:

$$
C_{L M}^{*}=\frac{C_{L M}}{2 \sqrt{K_{L M}^{*} \frac{I_{L}}{r_{L}^{2}}}}
$$

This method reveals a non-dimensional and independent parameter $C_{L M}^{*}$. This parameter cannot easily be predicted before experimentation but it can be accepted as being in the band from 1 to 5 percent.

For several industrial applications this dissipative model can be added or replaced by a friction model with an internal state variable ([30], [31], [16]). $\left(C_{L M}^{*}=0.04 ; C_{L M}=67\right.$ N.s.m $\left.{ }^{-1}\right)$.

The model described in [30] was successfully tested but not retained in the final presented model in order to preserve the simplicity of the global model. More over, the accuracy needed for the dissipation function in this study does not justify the introduction of new parameters.

The complete dissipative function is defined by 5 parameters $\left(r_{L}\right.$, $\left.r_{M}, C_{L M}, \epsilon, G\right)$ and 4 variables $\xi_{L}, \xi_{M}, \dot{\xi}_{L}$ and $\dot{\xi}_{M}$.

$C_{\xi}\left(\theta_{M}, \theta_{L}, \dot{\theta}_{M}, \dot{\theta}_{L}\right)$ is completely defined by 3 parameters $\left(C_{L M}\right.$, $\epsilon, G$ )and produces a dissipative force proportional to the velocity of the impact.

$C$ is the viscous coefficient for dissipative behaviour introduced by a lubricant between the loose gear and the shaft. This coefficient can be identified with an analytic fluid model between two infinite cylinders or with a simple measure of velocity when the loose gear is in free rotation (Fig .13).

With the intention of constructing independent parameters and to avoid coupling with $I_{L}$ parameter, the parametric identification is led on $C^{*}=C / I_{L}$ This method reveals an independent parameter $C^{*}$ and the time response for an initial velocity $S_{0}$ at 
$t_{0}$ is:

$$
S(t)=S_{0} e^{-C^{*}\left(t-t_{0}\right)}=S_{0} e^{-\frac{C}{I_{L}}\left(t-t_{0}\right)}
$$

$S(t)$ corresponds to computed dash-dot lines in red on Fig. .9 $\left(C^{*}=78 \mathrm{~s}^{-1} ; \mathrm{C}=0.025\right.$ N.s.m). When these dash-dot lines are compared with free motion episodes of the loose gear, they represent a good method to estimate the quality of the numerical identification of $\mathrm{C}$.

\section{Numerical and Experimental Comparison}

All simulations shown were performed with numerical values defined in section 7 for each parameter of the model built. In an effort to improve the graphic legibility and kinematical analysis, measured and simulated signals are studied between 0 $\mathrm{Hz}$ and $1000 \mathrm{~Hz}$ using classical filtering techniques $\left(10^{\text {th }}\right.$ order Cauer filter with phase compensations).

Three comparisons between the numerical simulations and the experimental measures are shown. Each comparison is defined by the excitation level of the main shaft and its frequency:

- $30 \mathrm{~Hz}, 300 \mathrm{Rad}^{-\mathrm{s}^{-2}} \mathrm{RMS}\left(12 \mathrm{~m} . \mathrm{s}^{-2}\right.$ amplitude peak on the pitch diameter of the main gear)

- $60 \mathrm{~Hz}, 300$ Rad.s ${ }^{-2}$ RMS (12 m.s ${ }^{-2}$ amplitude peak on the pitch diameter of the main gear)

- $30 \mathrm{~Hz}, 500 \mathrm{Rad}_{\mathrm{s}}{ }^{-2} \mathrm{RMS}\left(20 \mathrm{~m} . \mathrm{s}^{-2}\right.$ amplitude peak on the pitch diameter of the main gear)

Other comparisons were made for frequencies between $30 \mathrm{~Hz}$ and $60 \mathrm{~Hz}$ (by $2 \mathrm{~Hz}$ steps) and for several angular accelerations from 100 Rad.s ${ }^{-2}$ RMS to 700 Rad.s $^{-2}$. The presented comparisons cover a large field of significant cases with a high level of idle gear noise.

For each comparison, different kinds of kinematic results are shown: 
- acceleration on the pitch diameter of the loose gear

- velocity on the pitch diameter of the loose gear

- displacement on the pitch diameter of the loose gear

- transmission error in displacement between the main and loose gears.

\subsection{Initial Comparison: The Lower Limit Frequency Of Idle Gear Noise}

The first comparison is undertaken at an excitation frequency of $30 \mathrm{~Hz}$ and an acceleration of $300 \mathrm{Rad}_{\mathrm{s}}{ }^{-2} \mathrm{RMS}\left(12 \mathrm{~m} . \mathrm{s}^{-2}\right.$ amplitude peak on the pitch diameter of the main gear)

The comparison based on angular position or displacement along the pitch diameter ( $\xi$ axis) (Fig .12) shows a very strong correlation between experimental measurements and numerical simulations. Often in cases of dynamic systems, observations involving this kind of kinematic variable display a close fit between measurements and models. The comparison of kinematic variables had to be conducted with greater order derivatives to confirm the models.

The simulated velocity describes with precision levels and events during the dynamic simulation: synchronization of the different steps during the excitation, shocks and free motions, are predicted with strong accuracy (Fig .10).

Acceleration is the more convenient kinematic descriptor for impact identification and vibroacoustic prediction of complete structures. Acceleration levels and the number of impacts are accurately predicted. Simulated peaks decrease in accordance with measurements (Fig .11).

Another way to identify impacts and dynamic behaviour of gears is to represent the relative displacement between the main gear and the loose gear. This displacement results from the backlash between teeth shown by the gap between the two horizontal dashdotted lines on Fig .17, .19, .22. 
The second comparison is performed at a frequency of $60 \mathrm{~Hz}$ and an acceleration of 300 Rad.s ${ }^{-2}$ RMS (12 m.s $\mathrm{s}^{-2}$ amplitude peak on the pitch perimeter of the main gear).

The model's parameters are numerically the same as those used for the previous comparison and those identified in section 7 . The evolution of the frequency from $30 \mathrm{~Hz}$ to $60 \mathrm{~Hz}$ reduces the number of shocks from 4 or 5 to only 2 or 3 shocks each time on the same side. The level of acceleration does not change significantly as the frequency increases (Fig .13).

Transmission error clearly shows only two shocks on the same side of the tooth before changing sides (Fig .14). When the frequency increases the number of shocks on the same side is reduced and the length of free motion phases of the loose gear significantly shortens.

Velocity (Fig .15) is also correctly predicted in terms of magnitude and events by the numerical simulation.

\subsection{Third Comparison: Effect of an excitation level increase}

The third comparison is performed at a frequency of $30 \mathrm{~Hz}$ and an acceleration of $500 \mathrm{Rad} / \mathrm{s}^{2} \mathrm{RMS}\left(20 \mathrm{~m} . \mathrm{s}^{-2}\right.$ amplitude peak on the pitch perimeter of the main gear).

The model's parameters are numerically the same as those used for the previous comparisons and those identified in section 7 .

When the excitation magnitude increases, the number of shocks increases as does their acceleration magnitude (Fig .16).

Shock period and number can also be predicted from the transmission error diagram (Fig. .17). Shocks seem to happen over the interval $G$ between teeth (red dash-dotted lines). In fact, this effect is due to the coupling between dynamic behaviour of the loose gear and the non linear stiffness of its teeth (progression depending on manufacturing errors $\epsilon$ ).

When the excitation magnitude increases, the model maintains a 
${ }_{590}$ high level prediction for kinematic behaviour in terms of velocity

${ }_{591}$ (Fig .18).

${ }_{592}$ Another way to identify and quantify shocks is obtained in post

${ }_{593}$ processing velocities with the intention of measuring the relative

${ }_{594}$ velocity when shocks occur (Fig .19). This graph reinforces the

${ }_{595}$ analysis of shocks and can also permit one to quantify the ve-

${ }_{596}$ locity of each shock and thus, the kinematical energy of shocks

${ }_{597}$ and its evolutions in Rayleigh (dissipative) and potential (elastic)

598 Energy. 


\section{Conclusion}

- The experimental study outlines phenomena and parameters responsible for the idle gear noise.

- The model built is a non linear Single Degree Of Freedom in rotation composed of 9 independent and invariant parameters: The identification of each parameter can be performed with an analytical and numerical approach or by measurements on a single dynamic test. To find the independence of each parameter and for a better accuracy, identifications presented in section 7 are performed with reduced variables and parameters. In several cases these reduced parameters are dimensionless.

- All simulations were carried out with the same set of parameters and reveal a very close fit with experimental measurements. The kinematic of the impacts is well predictable in terms of magnitude, duration, for number of one-sided impacts as well as the decrease in the magnitude of each impacts.

- Both simulations and experimental measurements reveal the following important points:

- several impacts can often appear on one side of the gear mesh,

- the number of impacts on one side strongly depends on the angular displacement of the main shaft,

- the energy level of impacts mainly depends on the acceleration level of the main shaft oscillations,

- The excitation level at which impacts appear is identified, predicted and closely connected with the acoustic phenomenon called idle gear noise.

- The next step of this study is to undertake a vibroacoustic model of the gear box based on this study of a single couple of gears. The aim of this work is to show the predictable vibroacoustic behaviour of a complete gear box with a small number of (non linear) Degrees of Freedom.

\section{Acknowledgment}

The authors express their gratitude to Renault SA for the financial support of this study. 
[1] R.J.Comparin R.Singh, H.Xie. Analysis of automotive neutral gear rattle. Journal of Sound and Vibration, 131:177196, 1989.

[2] P.Velex P.Sainsot. An analytical study of tooth friction excitations in errorless spur and helical gears. Mechanism and machine theory, 37:641-658, 1996.

[3] M.-C. Pan H. Van Brussel P. Sas. Intelligent joint fault diagnosis of industrial robots. Mechanical Systems and Signal Processing, 12(4):571-588, 1998.

[4] T. Tjahjowidodo F. Al-Bender H. Van Brussel. Experimental dynamic identification of backlash using skeleton methods. Mechanical Systems and Signal Processing, 21:959-972, 2007.

[5] I. Tawfiq T. Vinh. Contribution to the extension of modal analysis to non-linear structure using volterra functional series. Mechanical Systems and Signal Processing, 17(2):379407, 2003.

[6] Jeffrey L. Stein Churn-Hway Wang. Automatic detection of clearance in mechanical systems: Experimental validation. Mechanical Systems and Signal Processing, 10(4):395-412, 1996.

[7] R.M. Lin D.J. Ewins. Chaotic vibration of mechanical systems with backlash. Mechanical Systems and Signal Processing, 7(3):257-272, 1993.

[8] I. Trendafilova H. Van Brussel. Non-linear dynamics tools for the motion analysis and condition monitoring of robot joints. Mechanical Systems and Signal Processing, 15(6):1141-1164, 2001.

[9] T. Tjahjowidodo F. Al-Bender H. Van Brussel. Quantifying chaotic responses of mechanical systems with backlash component. Mechanical Systems and Signal Processing, 21:973993, 2007.

[10] M. Ajmi P.Velex. model for simulating the quasi-static and dynamic behaviour of solid wide-faced spur and helical gears. 

Mechanism and Machine Theory, 40:173-190, 2005.

[11] A.Al shyyab A.Kahraman. Non-linear dynamic analysis of multi-mesh gear train using multi-term harmonic balance method: sub-harmonic motions. Journal of Sound and Vibration, 279:417-451, 2005.

[12] J.P.Raclot P.Velex. Simulation of dynamic behaviour of single and multi-stage geared systems with shape deviations and mounting errors by using a spectral method. Journal of Sound and Vibration, 220(5):861-903, 1999.

[13] J.Blomqvist W.Kropp. Detection of rattle sources in gearbox using correlation technique. acta acustica, 87:77-85, 2001.

[14] N.Driot E.Rigaud J.Sabot. Allocation of gear tolerances to minimize gearbox noise variability. acta acustica, 87:67-76, 2001.

[15] M.Barthod J.L.Tébec J.C.Pin. étude de l'influence des caractéristiques de l'acyclisme sur le bruit de "graillonnement" dans les boites de vitesses automobiles. In Congrès "Vibrations, Chocs et Bruit", 2002.

[16] N.Barabanov R.Ortega. A new model for control of systems with friction. IEEE Transactions on automatic control, 45(4):830-832, 2000.

[17] P.Ducret J.Sabot. Calcul du bruit rayonné par les carters des transmissions à engrenages : méthode et applications. acustica, 84:97-107, 1998.

[18] P.Velex M.Maatar. A mathematical model for analysing the influence of shape deviations and mounting error on gear dynamic behaviour. Journal of Sound and Vibration, 191(5):629-660, 1996.

[19] T.C.Lim R.Singh. A review of gear housing dynamics and acoustics literature. NASA report, 1989.

[20] T.C.Lim R.Singh. Vibration transmission through rolling element bearing, part i : Bearing stiffness formulation. Journal of Sound and Vibration, 139(2):179-199, 1990.

[21] T.C.Lim R.Singh. Vibration transmission through rolling element bearing, part ii : System studies. Journal of Sound and Vibration, 139(2):201-225, 1990. 
[22] T.C.Lim R.Singh. Vibration transmission through rolling element bearing, part iii : Geared rotor system studies. Journal of Sound and Vibration, 151(1):31-54, 1991.

[23] T.C.Lim R.Singh. Vibration transmission through rolling element bearing, part iv : Statistical energy analysis. Journal of Sound and Vibration, 153(1):37-50, 1992.

[24] G.Henriot. Quelques réflexions sur la génération du bruit et des vibrations dans les engrenages. Mécanique industrielle et Matériaux, 49(3):125-129, 1996.

[25] F.Robbe-Valloire R.Progri B.Paffoni R.Gras. Modélisation de la topologie microgéométrique. Matériaux et Techniques, 3-4, 2000.

[26] R.E.Crochiere L.R.Rabiner. Multi-rate signal processing. Prentice-Hall, pages 88-91, 1983.

[27] H.Hertz. Ueber die beruhung fester elastischer korper. Journal fur die reine und angewandte, Section Mathematic, 92:156-171, 1881.

[28] T.A. Harris. Rolling bearing analysis. John Wiley and Sons, 1991.

[29] J.-L.Dion J.-B.Casimir. Modélisation du comportement dynamique de clapets de compresseurs en état flexible. Mécanique et Industrie, 4:125-132, 2003.

[30] P.Dahl. Solid friction damping of mechanical vibrations. AIAA Journal, 14(2):1675-1682, 1976.

[31] C.Canudas de Wit H.Olsson K.J.Aström P.Lischinsky. A new model for control of systems with friction. IEEE Transactions on automatic control, 40(3), 1995. 


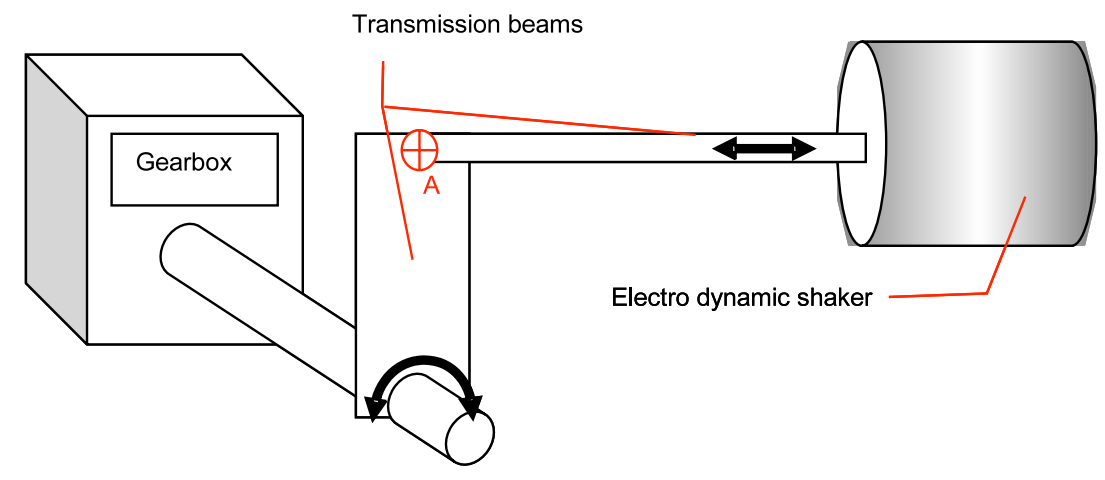

Fig .1. Schematic diagram of the experimental setup 


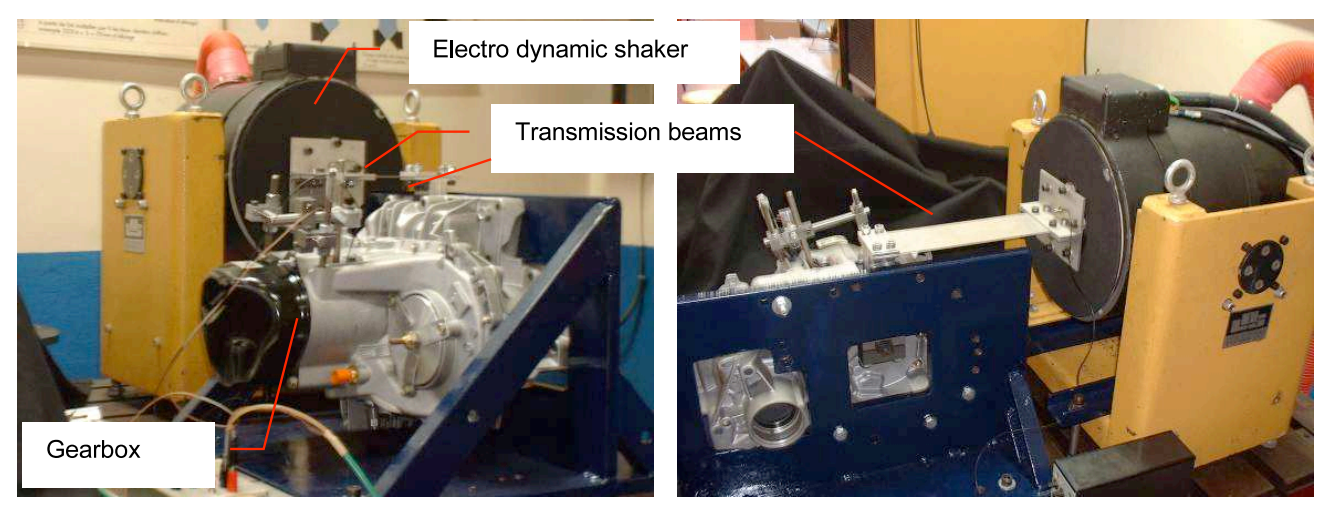

Fig .2. Pictures of the experimental setup 


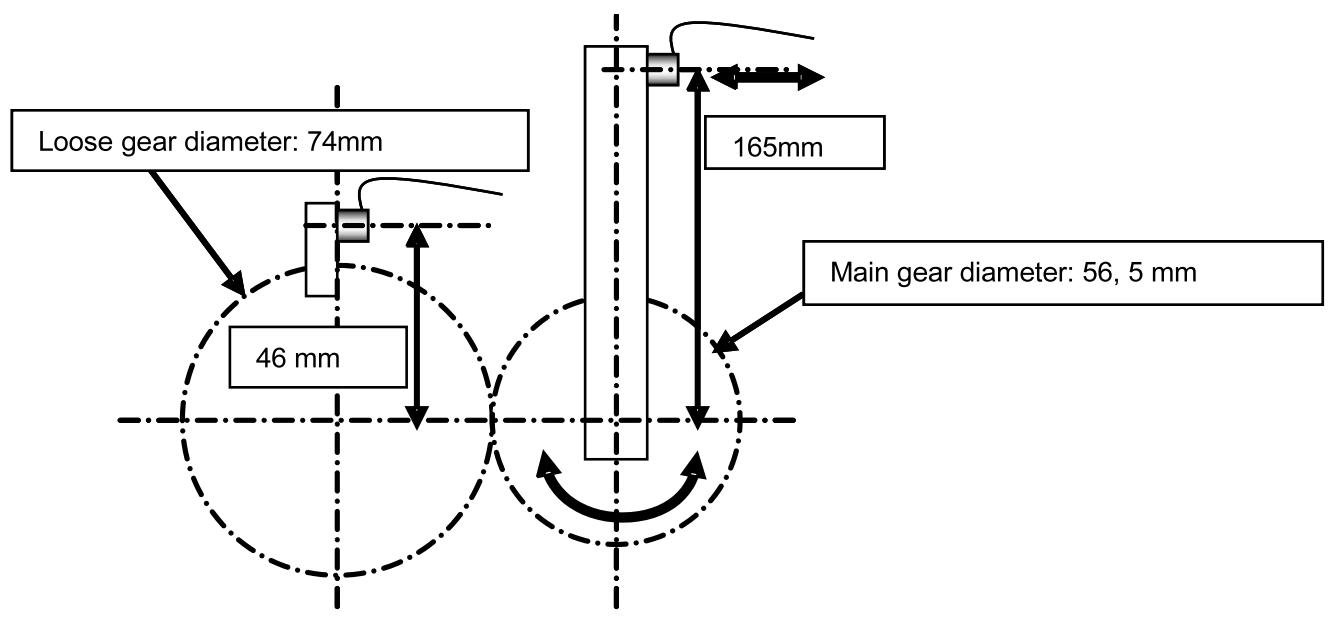

Fig .3. Schematic diagram of gear configuration 


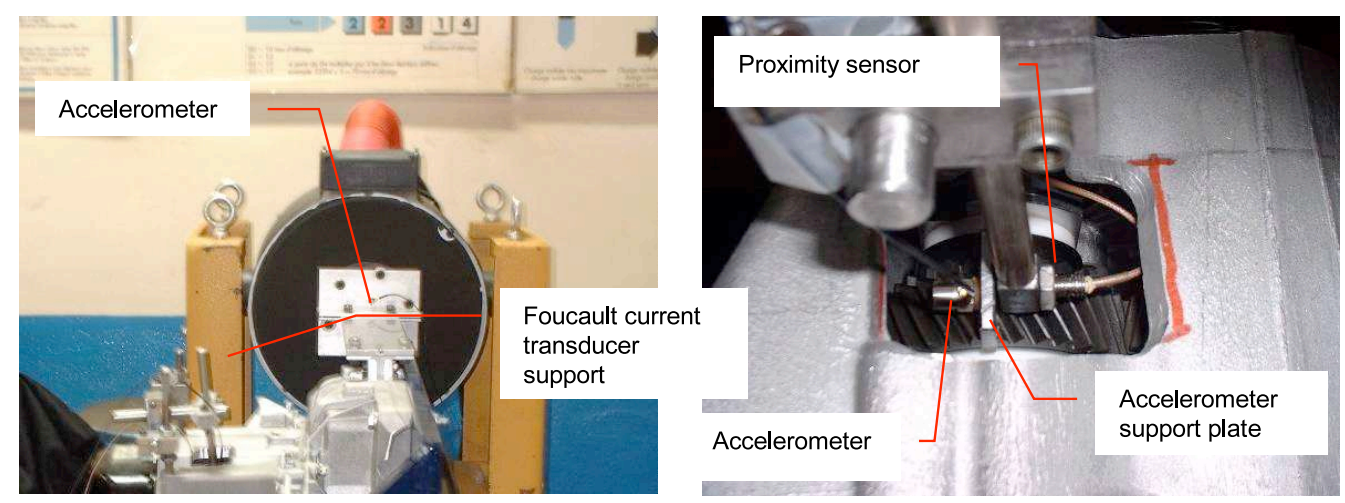

Fig .4. Intrumentation 

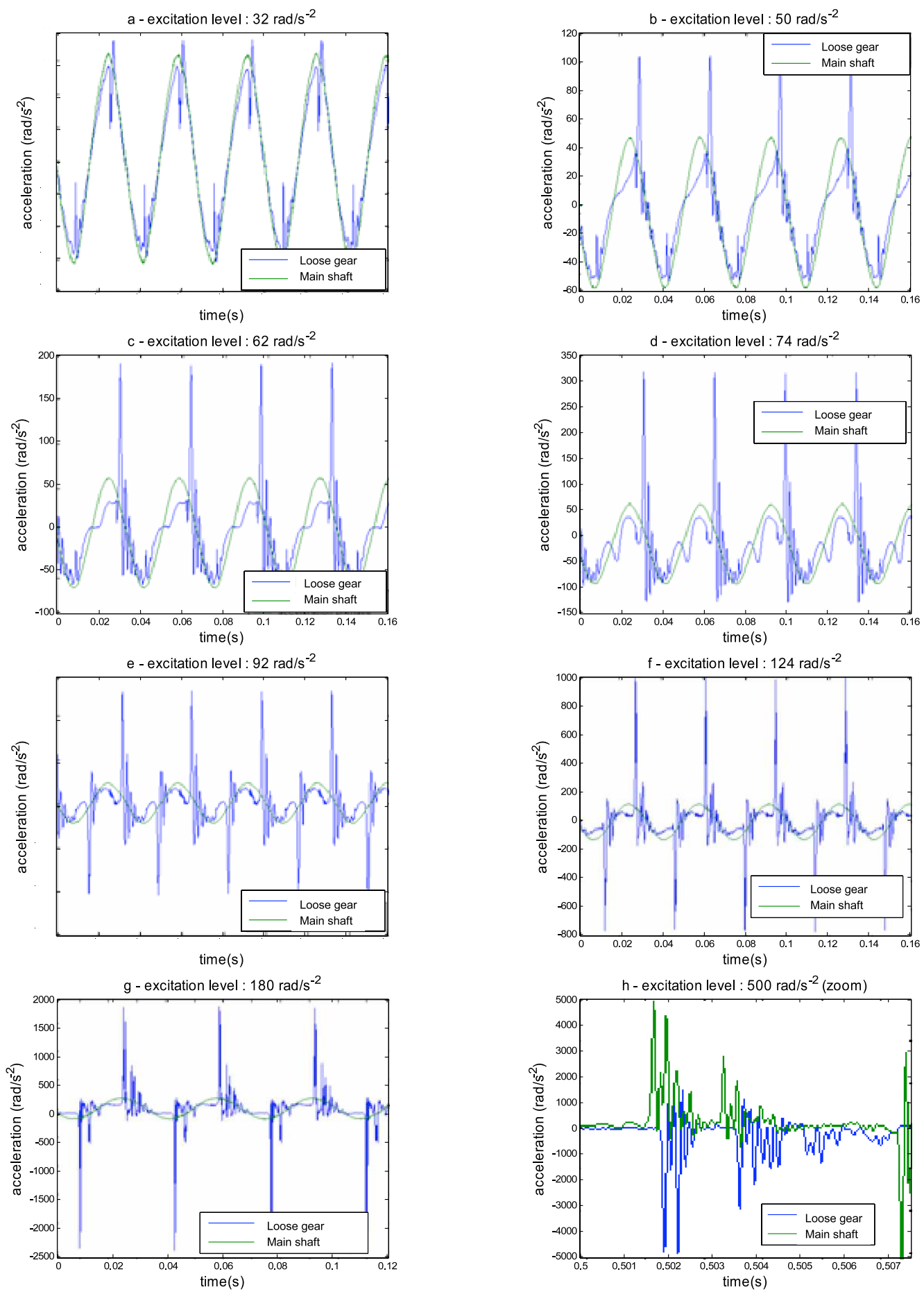

Fig .5. Temporal signals for different levels of a $30 \mathrm{~Hz}$ excitation 

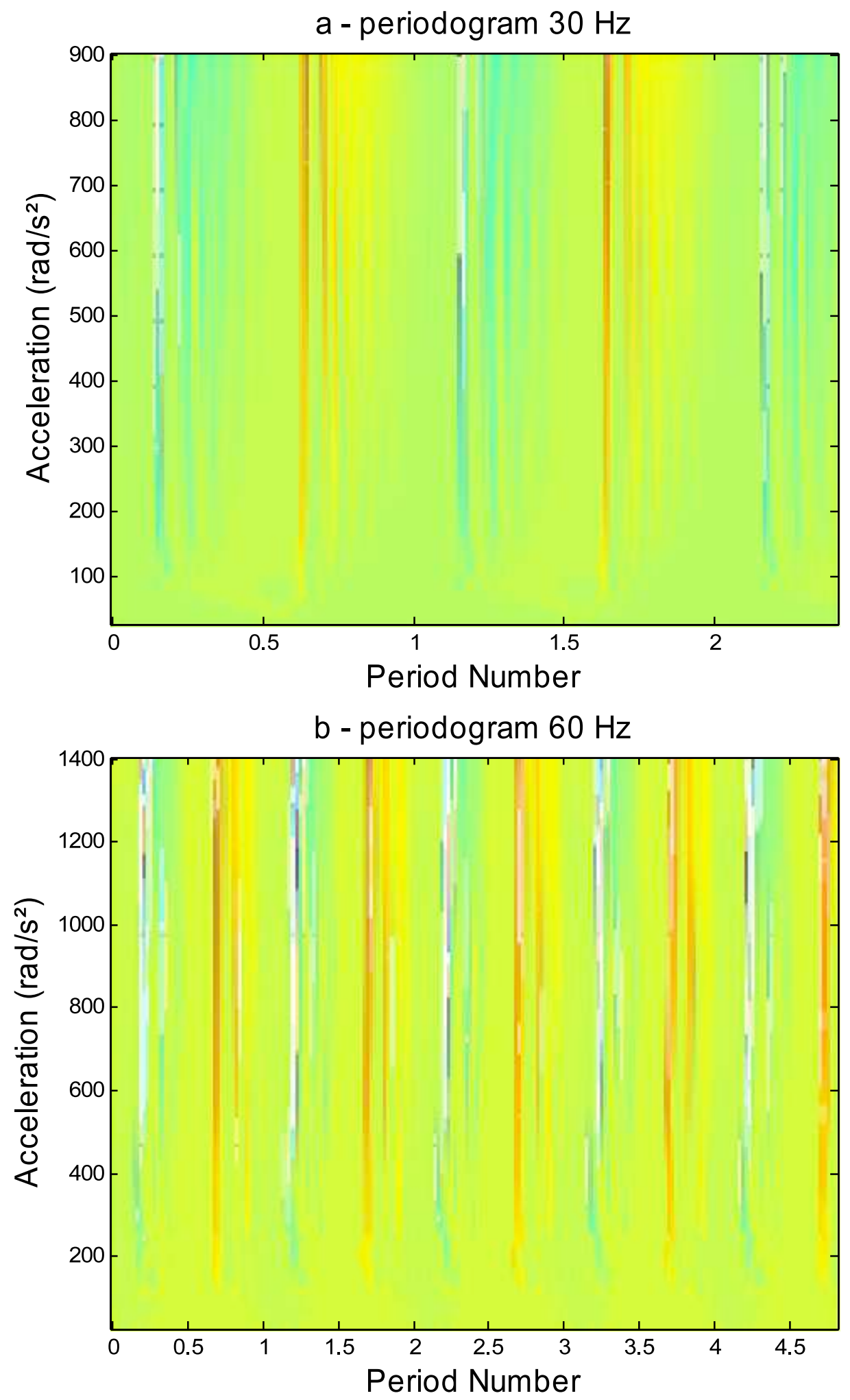

Fig .6. Evolution of shocks shape versus excitation level, for two different excitation frequencies. "Periodograms". 

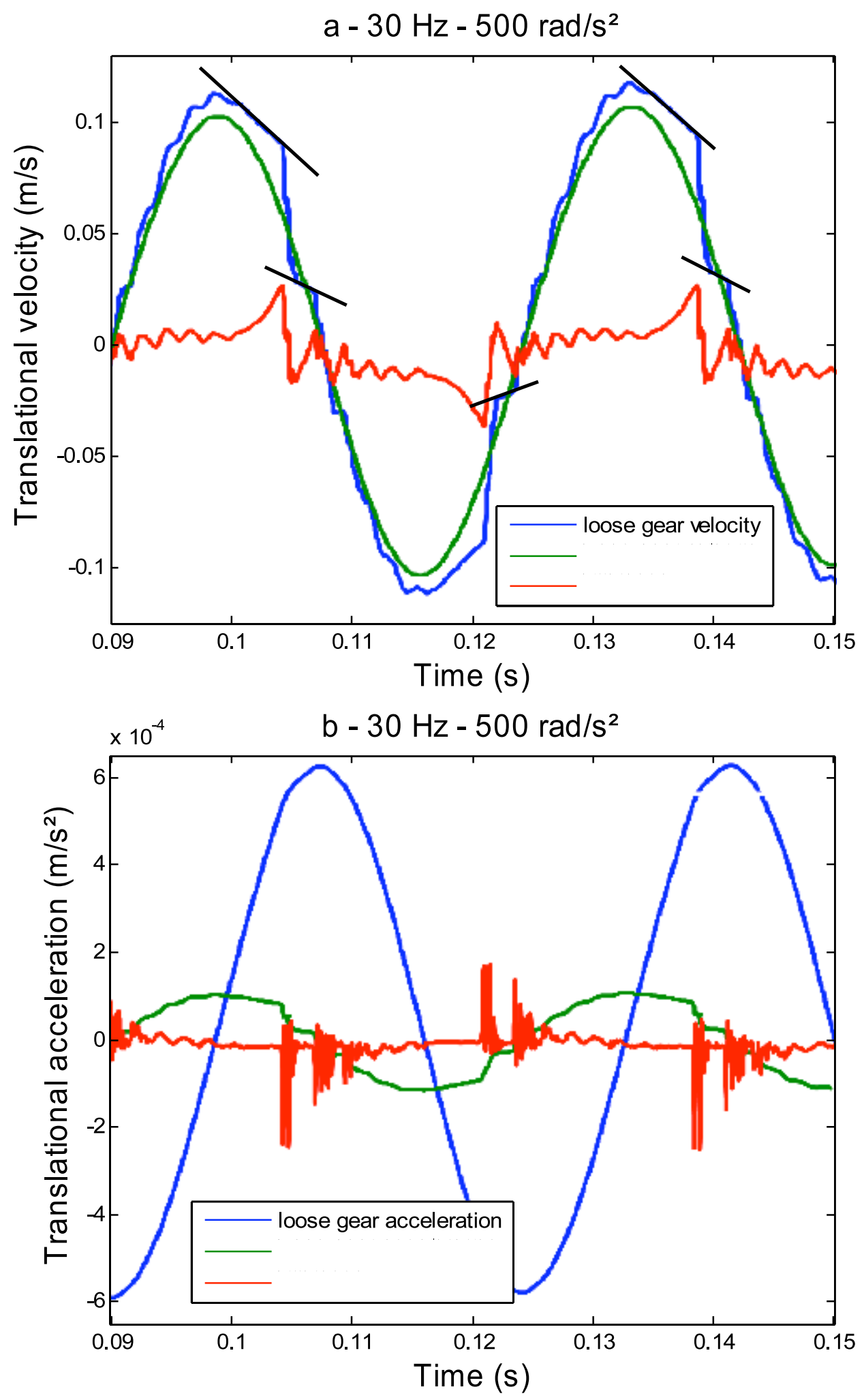

Fig .7. Kinetical gear behaviour for a $30 \mathrm{~Hz}-500 \mathrm{rad} / \mathrm{s}^{2}$ excitation 

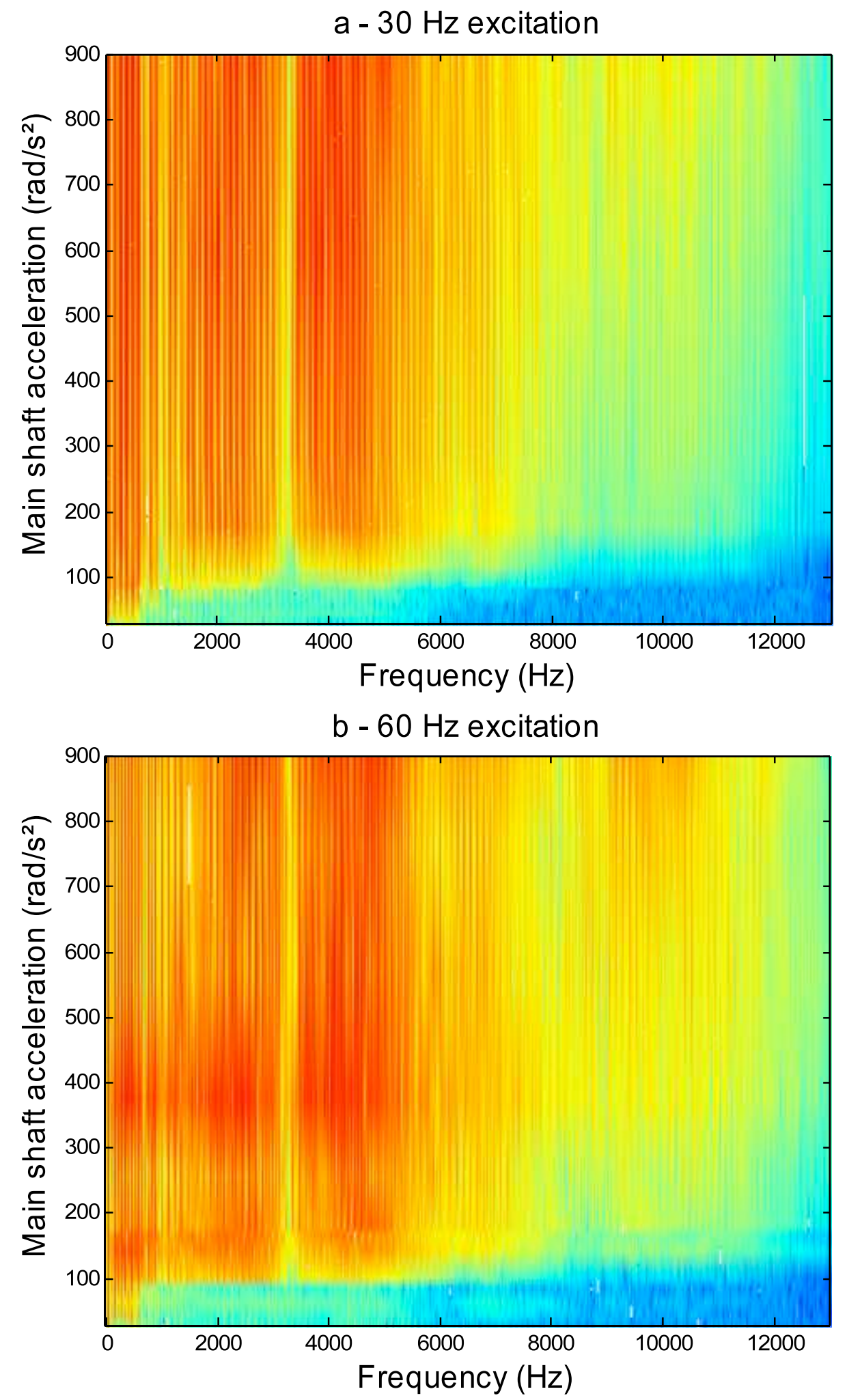

Fig .8. Evolution of loose gear acceleration spectral shape versus main shaft acceleration level 

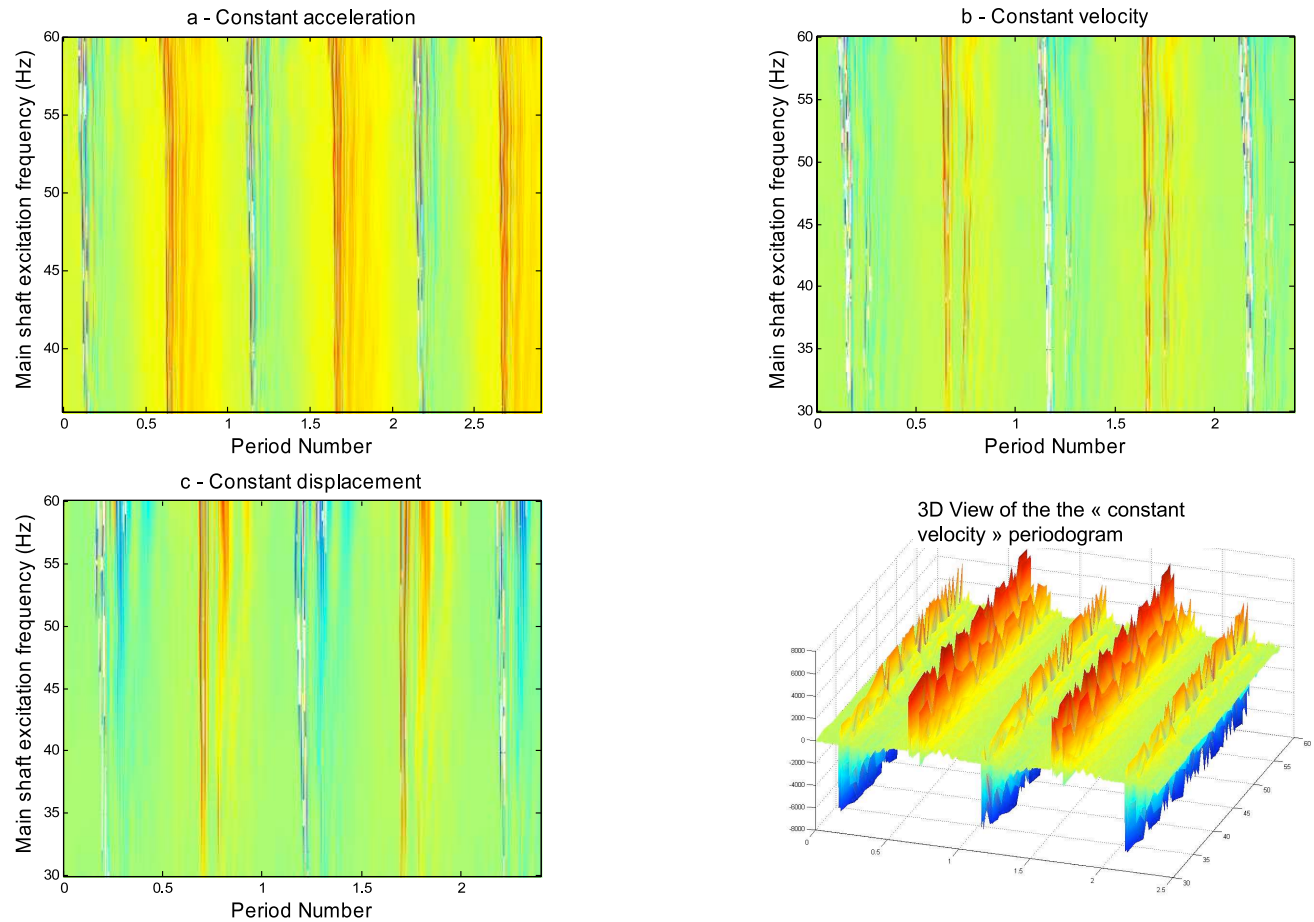

Fig .9. Loose gear acceleration shape evolution according to excitation frequency 


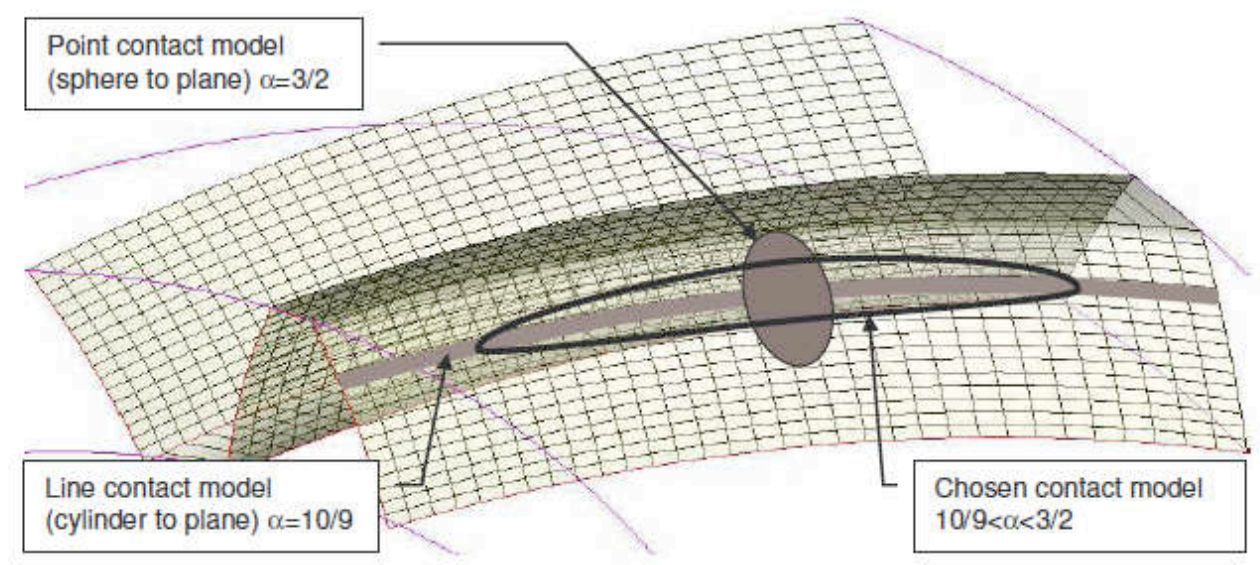

Fig .10. Contact areas for several models 


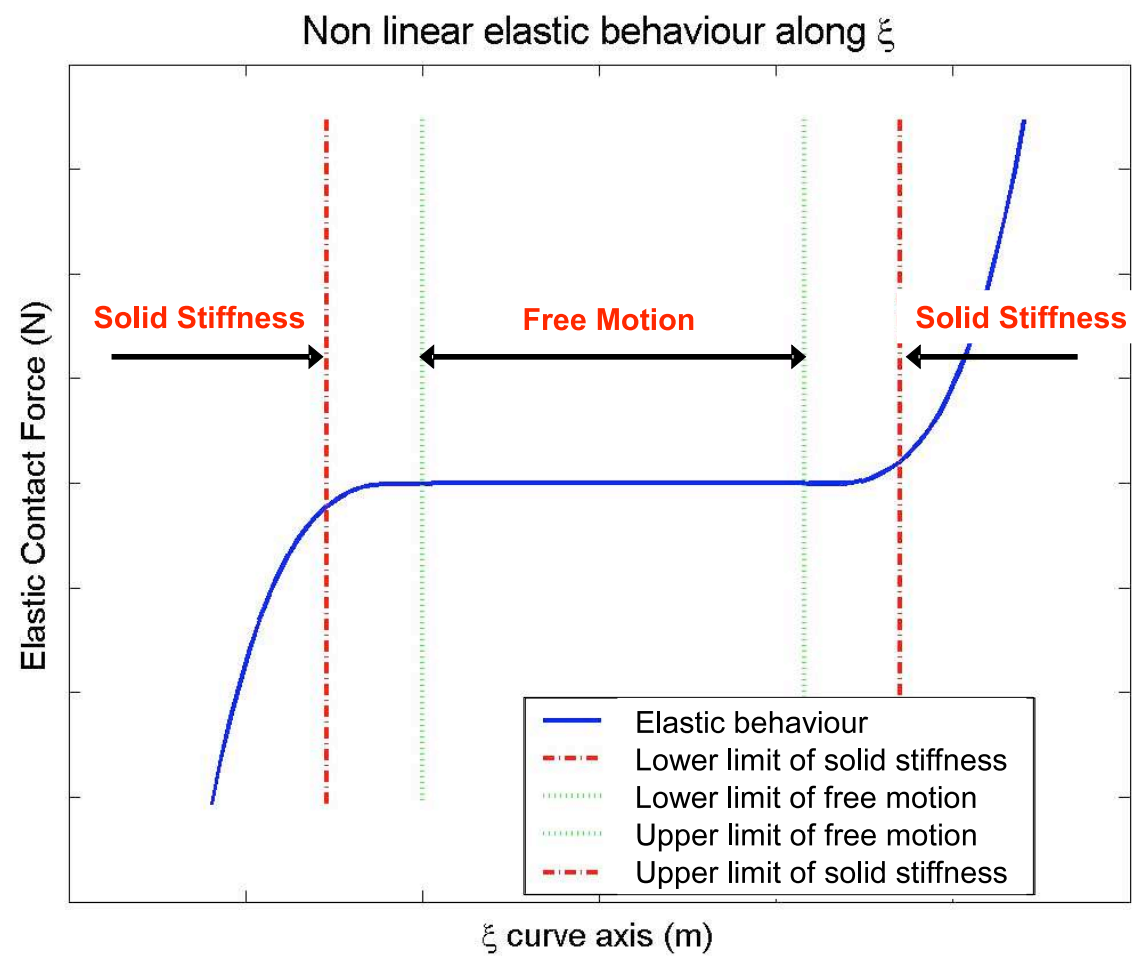

Fig .11. Elastic Behaviour on pitch perimeter 

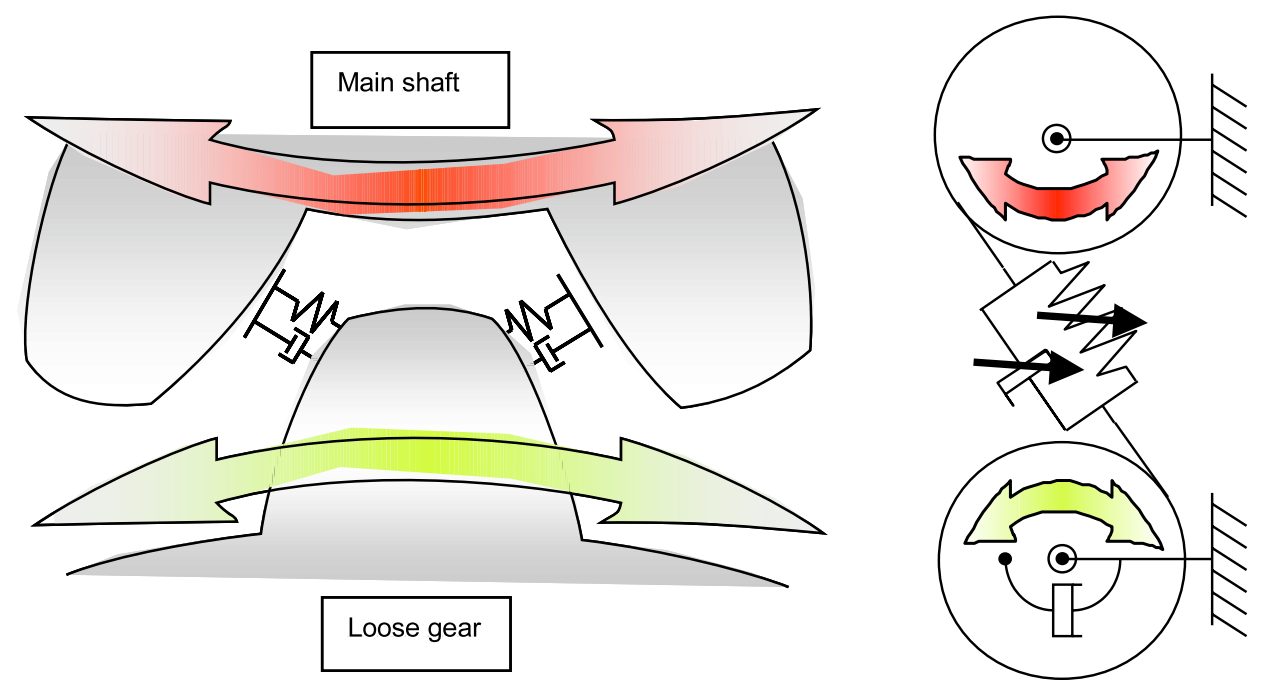

Fig .12. Schematic representations of gears in contact 


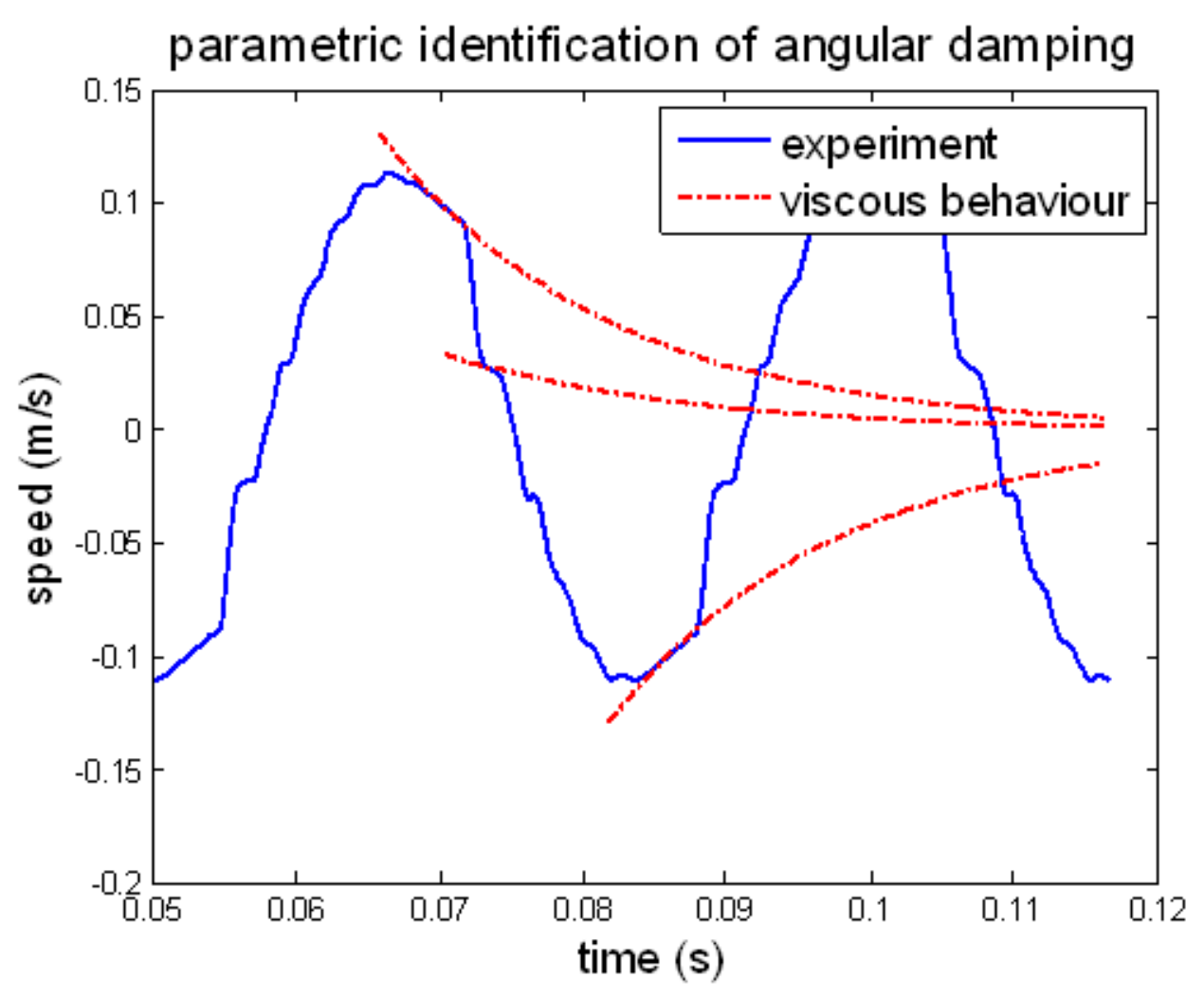

Fig .13. Parametric identification of rational damping based on experimental results 


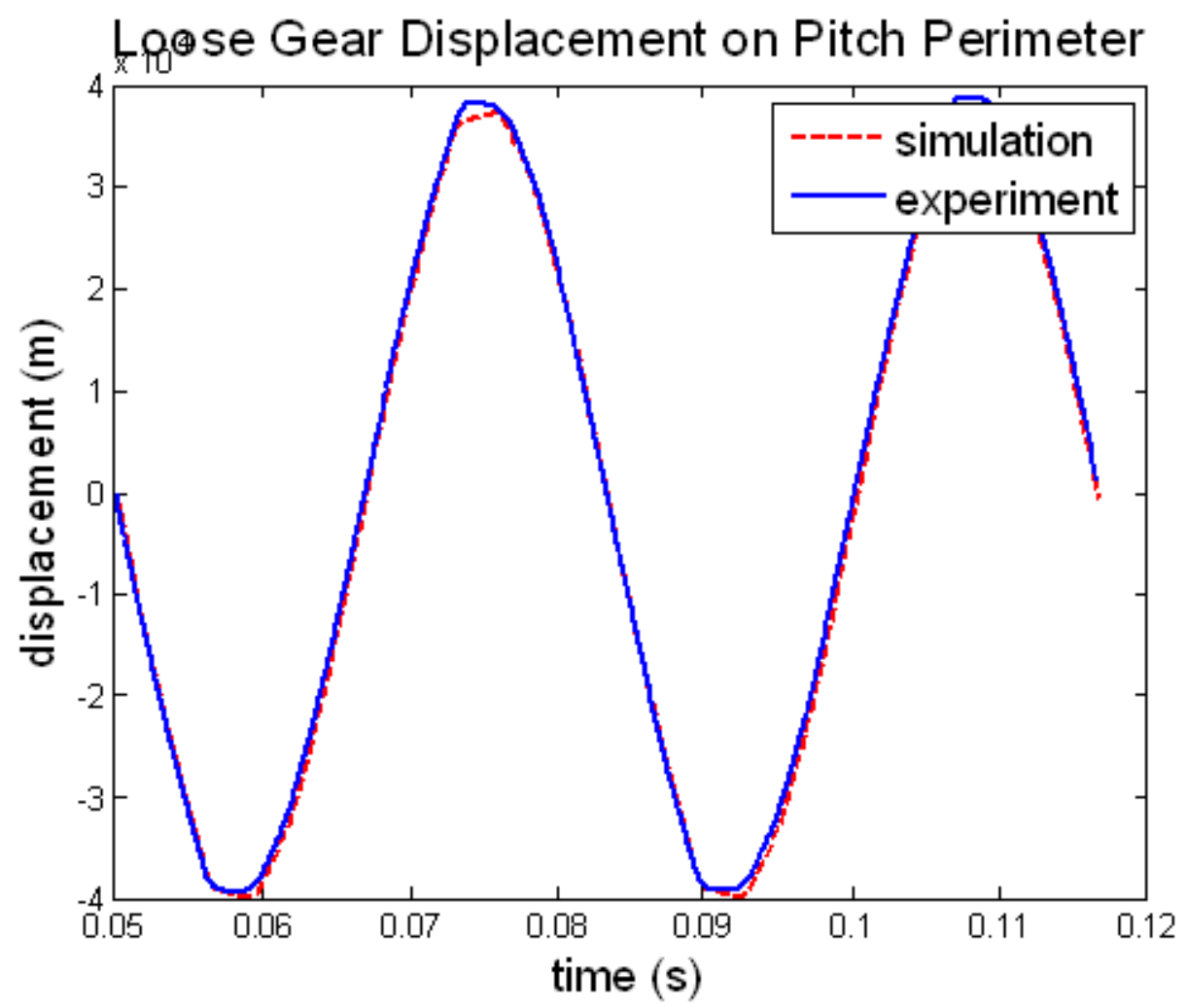

Fig .14. Comparison between measurements and simulation - Displacements for 30 $\mathrm{Hz}$ and $300 \mathrm{Rad} \mathrm{s}^{-2}$ 


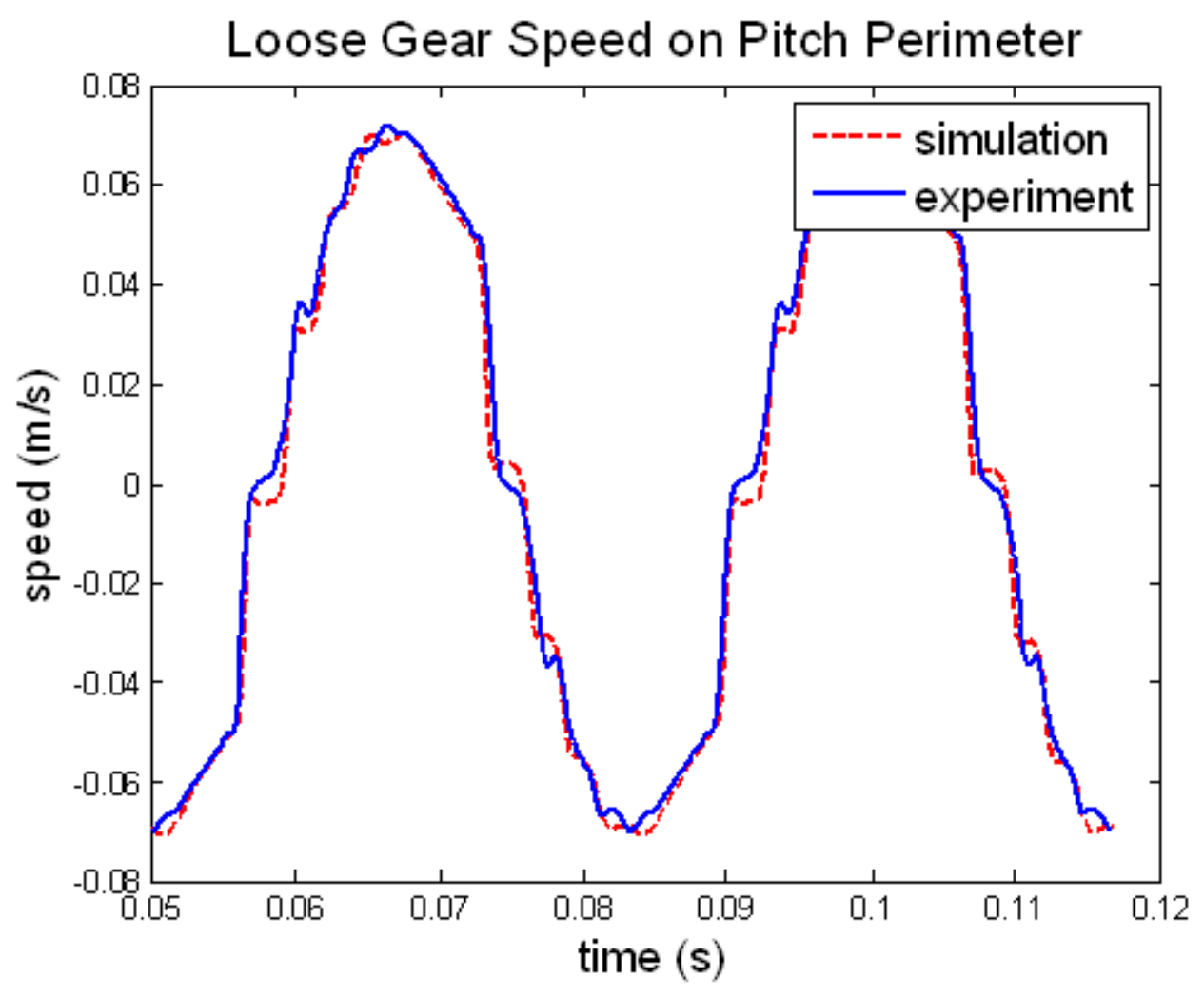

Fig .15. Comparison between measurements and simulation - Velocity for $30 \mathrm{~Hz}$ and $300 \operatorname{Rad~s}^{-2}$ 


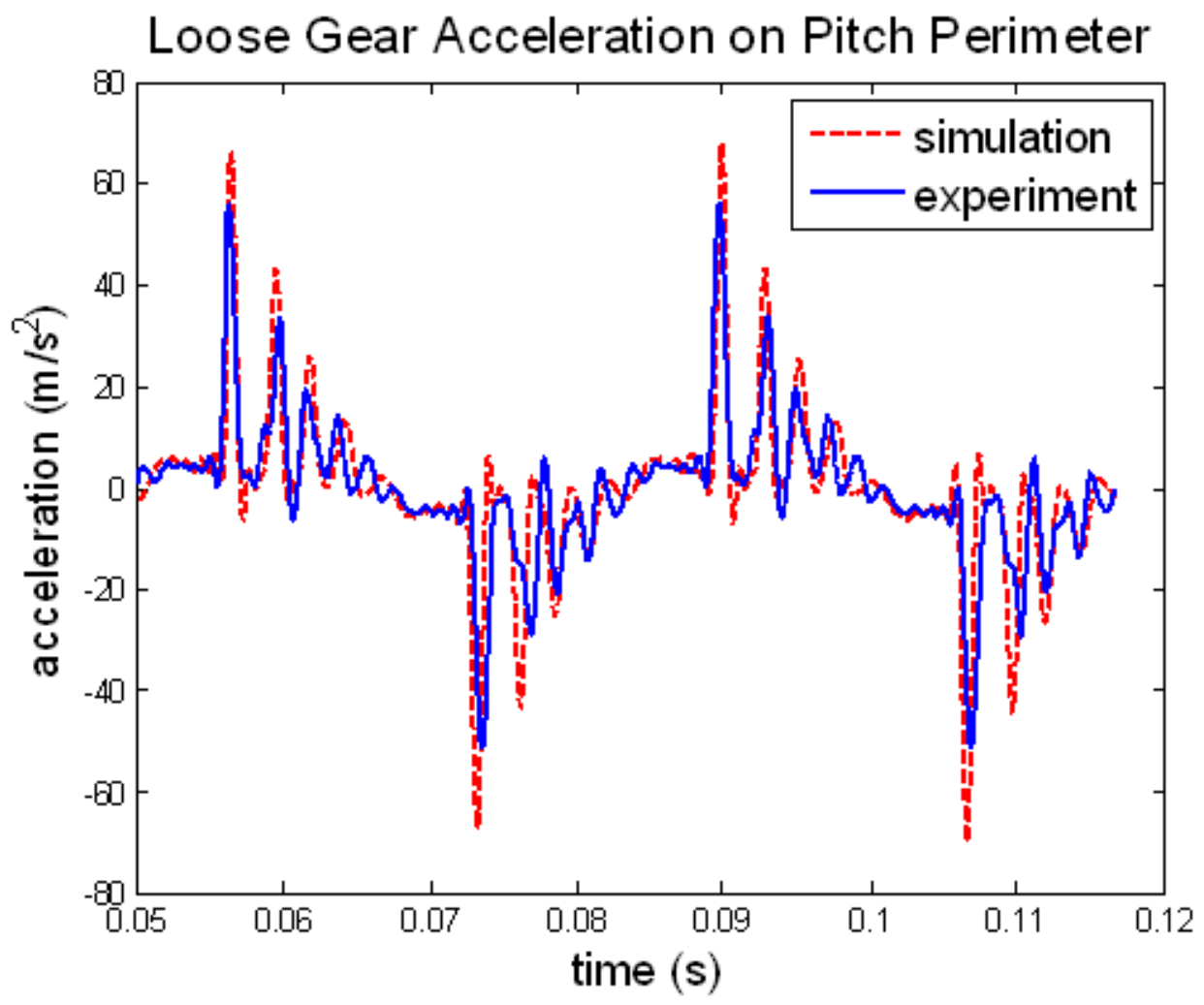

Fig .16. Comparison between measurements and simulation - Acceleration for 30 $\mathrm{Hz}$ and $300 \mathrm{Rad} \mathrm{s}^{-2}$ 


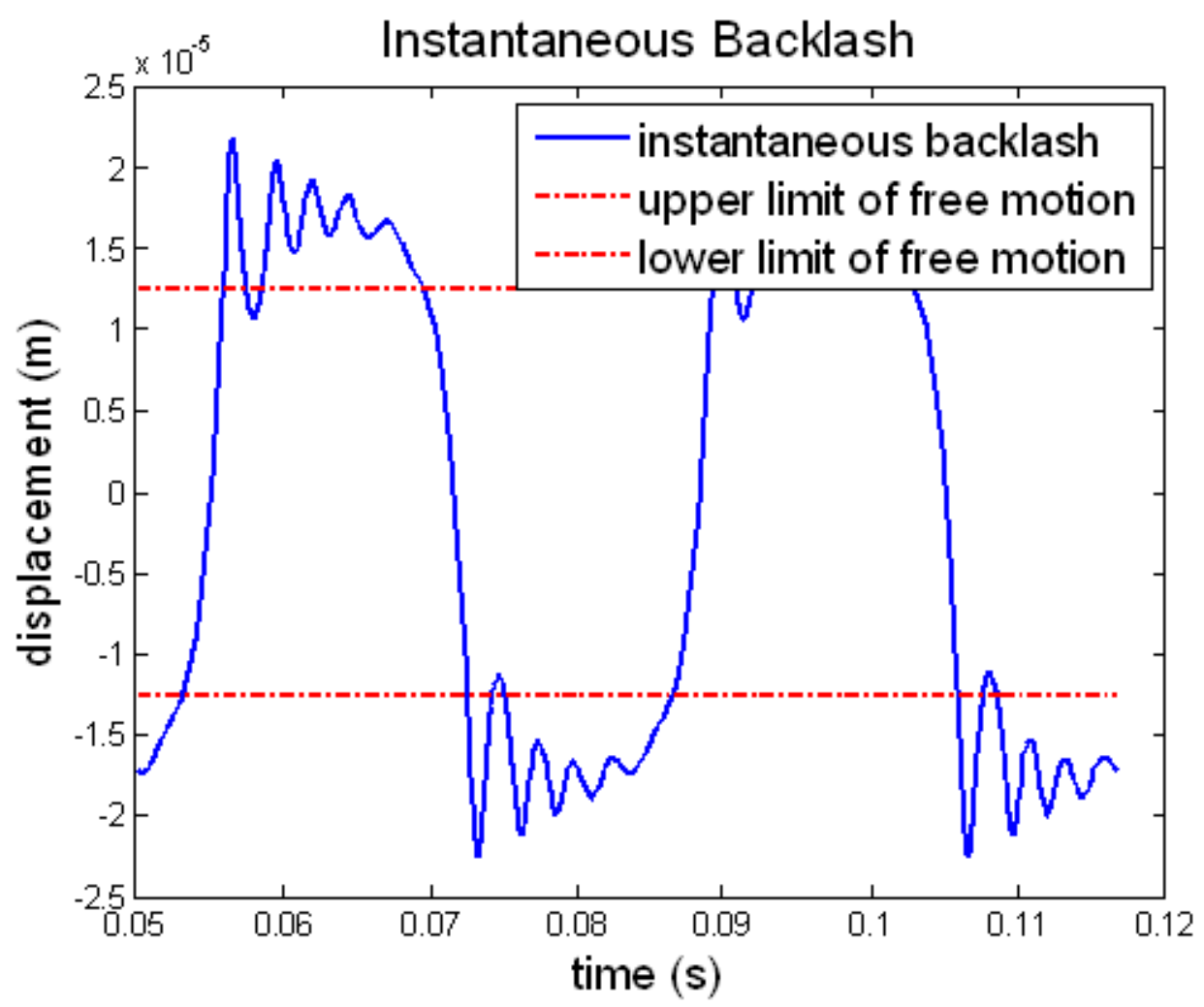

Fig .17. Relative displacement (instantaneous backlash) for $30 \mathrm{~Hz}$ and $300 \mathrm{Rad} \mathrm{s}^{-2}$ 


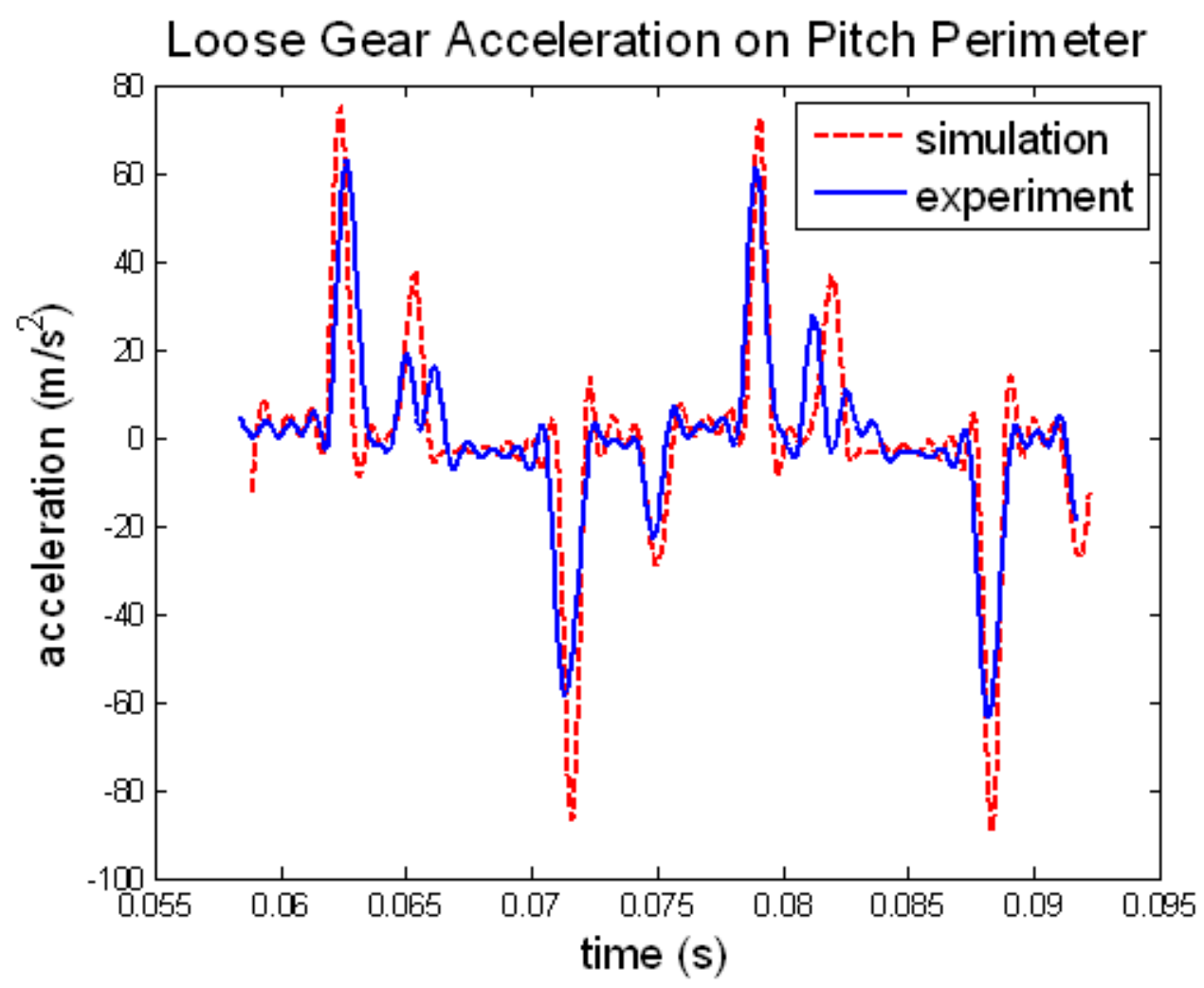

Fig .18. Comparison between measurements and simulation - Acceleration for 60 $\mathrm{Hz}$ and 300 Rad.s ${ }^{-2}$ 


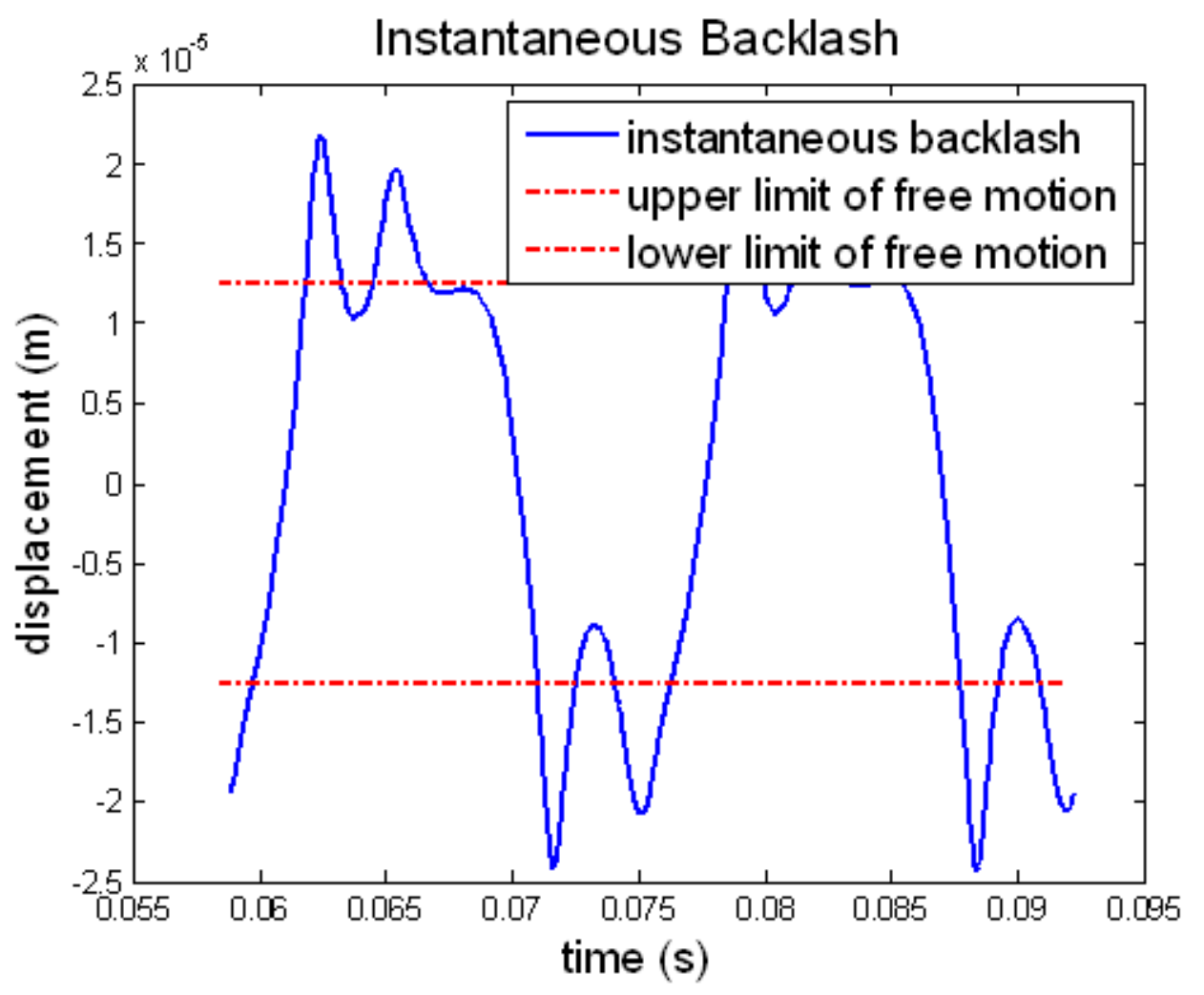

Fig .19. Comparison between measurements and simulation - Relative displacement (instantaneous backlash) for $60 \mathrm{~Hz}$ and $300 \mathrm{Rad} \mathrm{s}^{-2}$ 


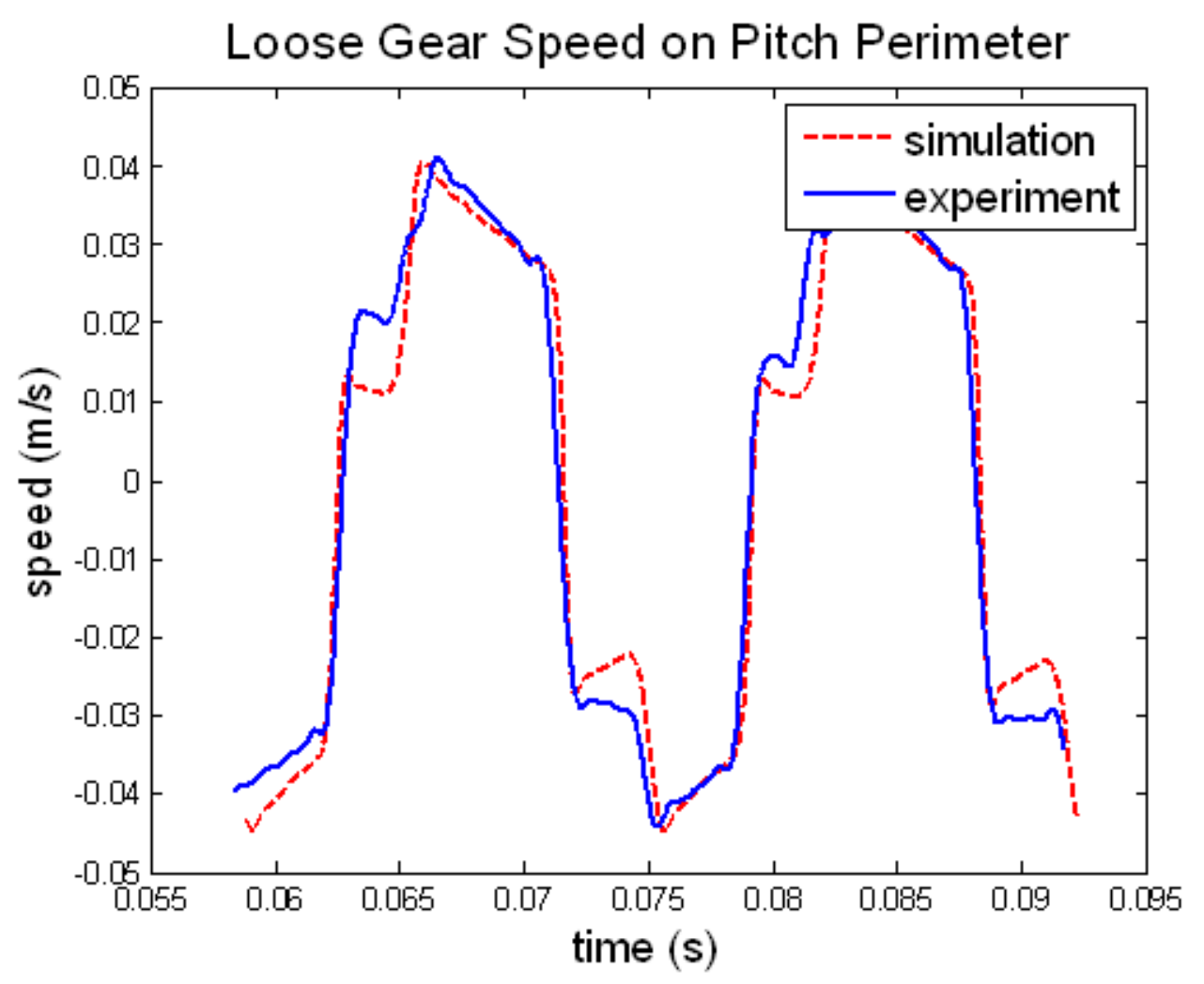

Fig .20. Comparison between measurements and simulation - Velocity for $60 \mathrm{~Hz}$ and $300 \operatorname{Rad}^{2}$ 


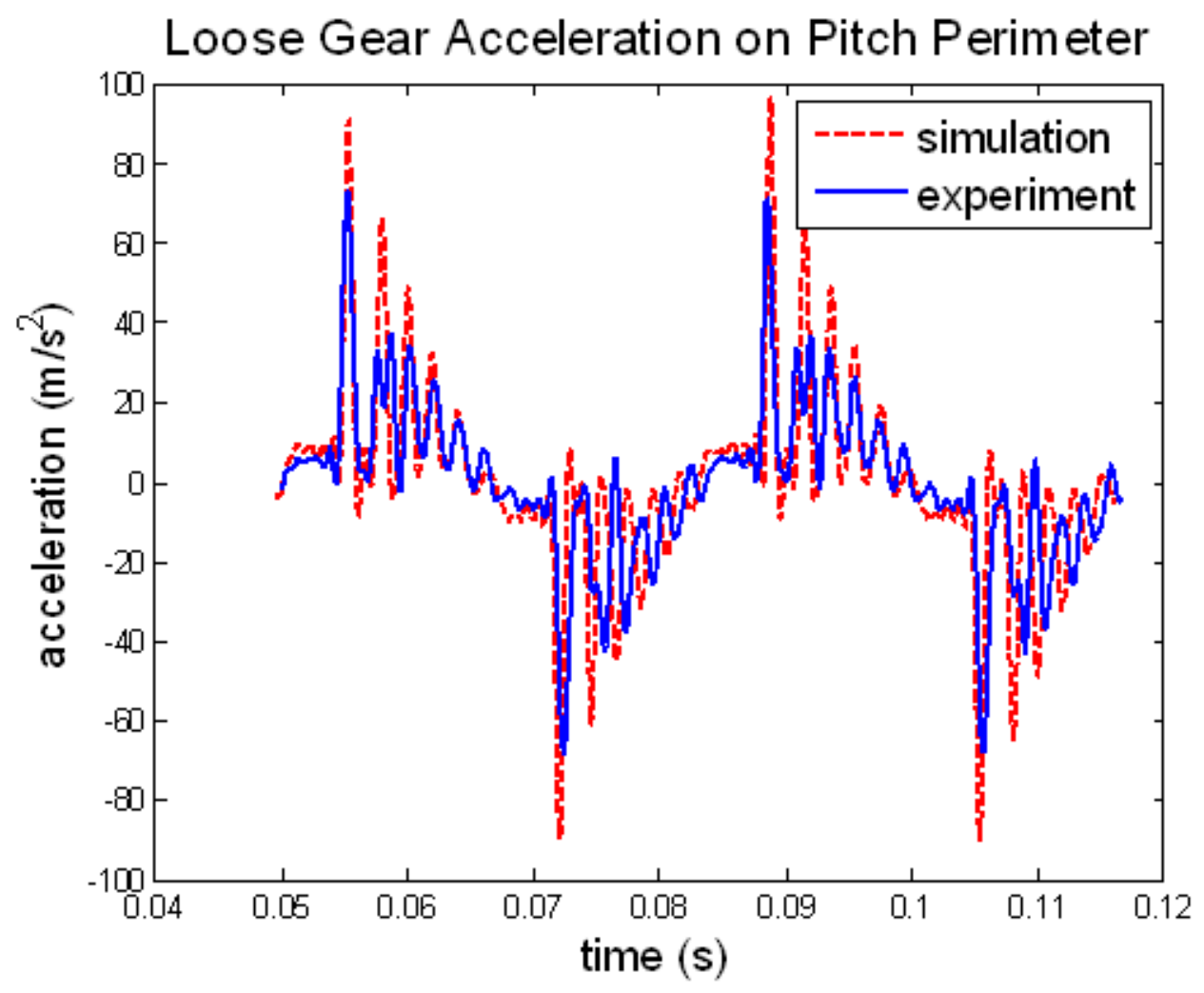

Fig .21. Comparison between measurements and simulation - Acceleration for 30 $\mathrm{Hz}$ and $500 \mathrm{Rad}^{2}$ 


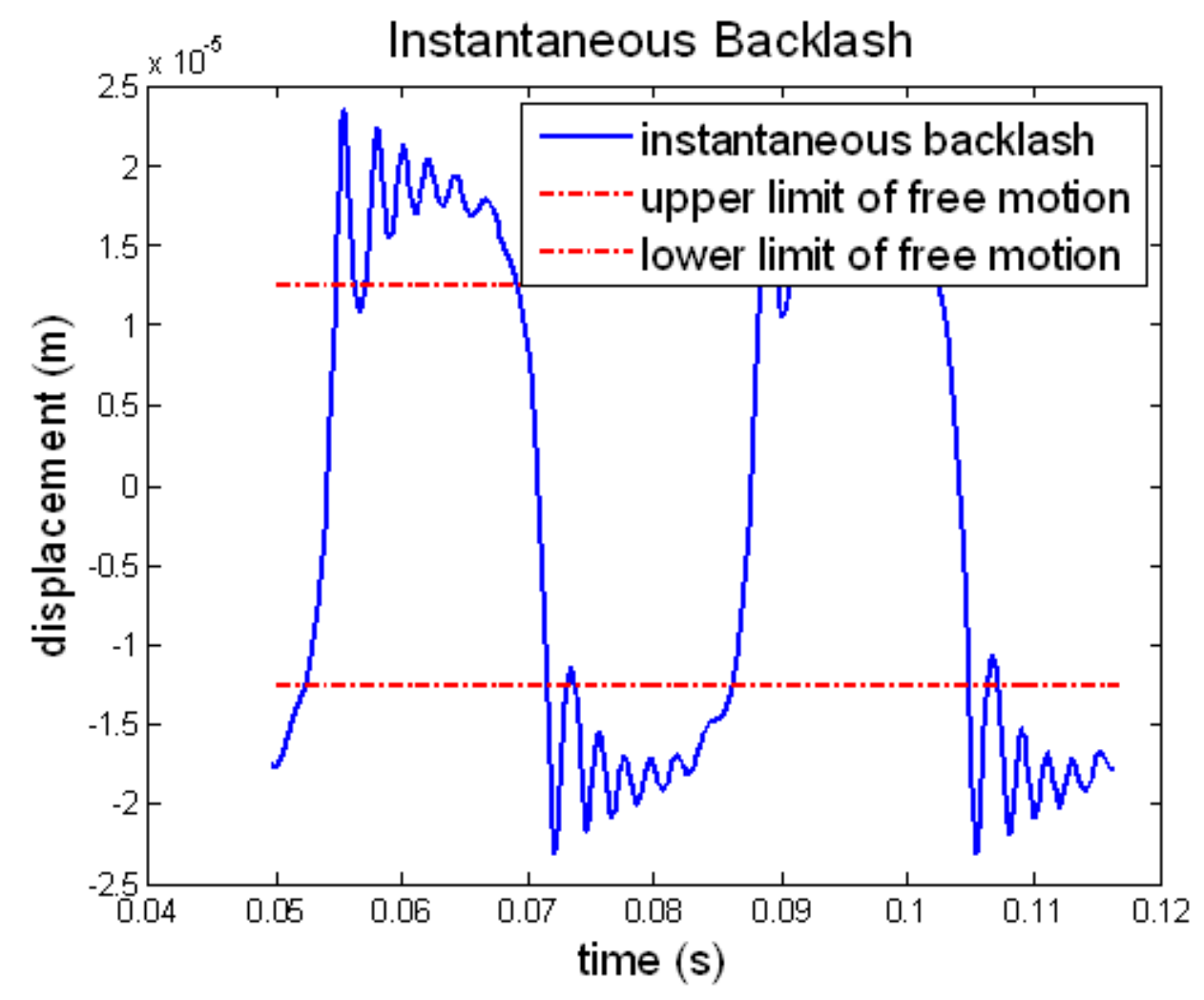

Fig .22. Comparison between measurements and simulation - Relative displacement (instantaneous backlash) for $30 \mathrm{~Hz}$ and $500 \mathrm{Rad} \mathrm{s}^{2}$ 


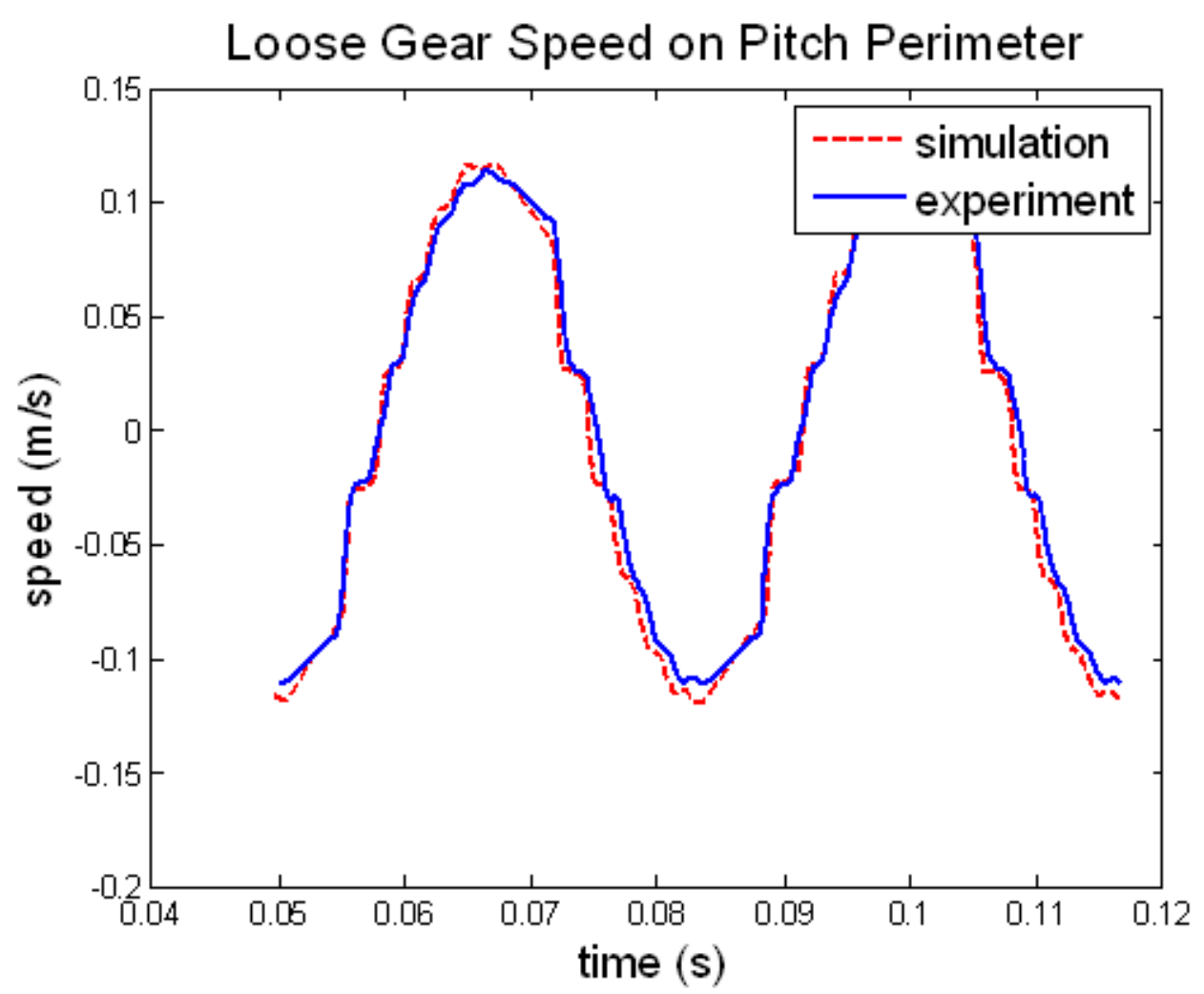

Fig .23. Comparison between measurements and simulation - Velocity for $30 \mathrm{~Hz}$ and $500 \operatorname{Rad~s}^{2}$ 


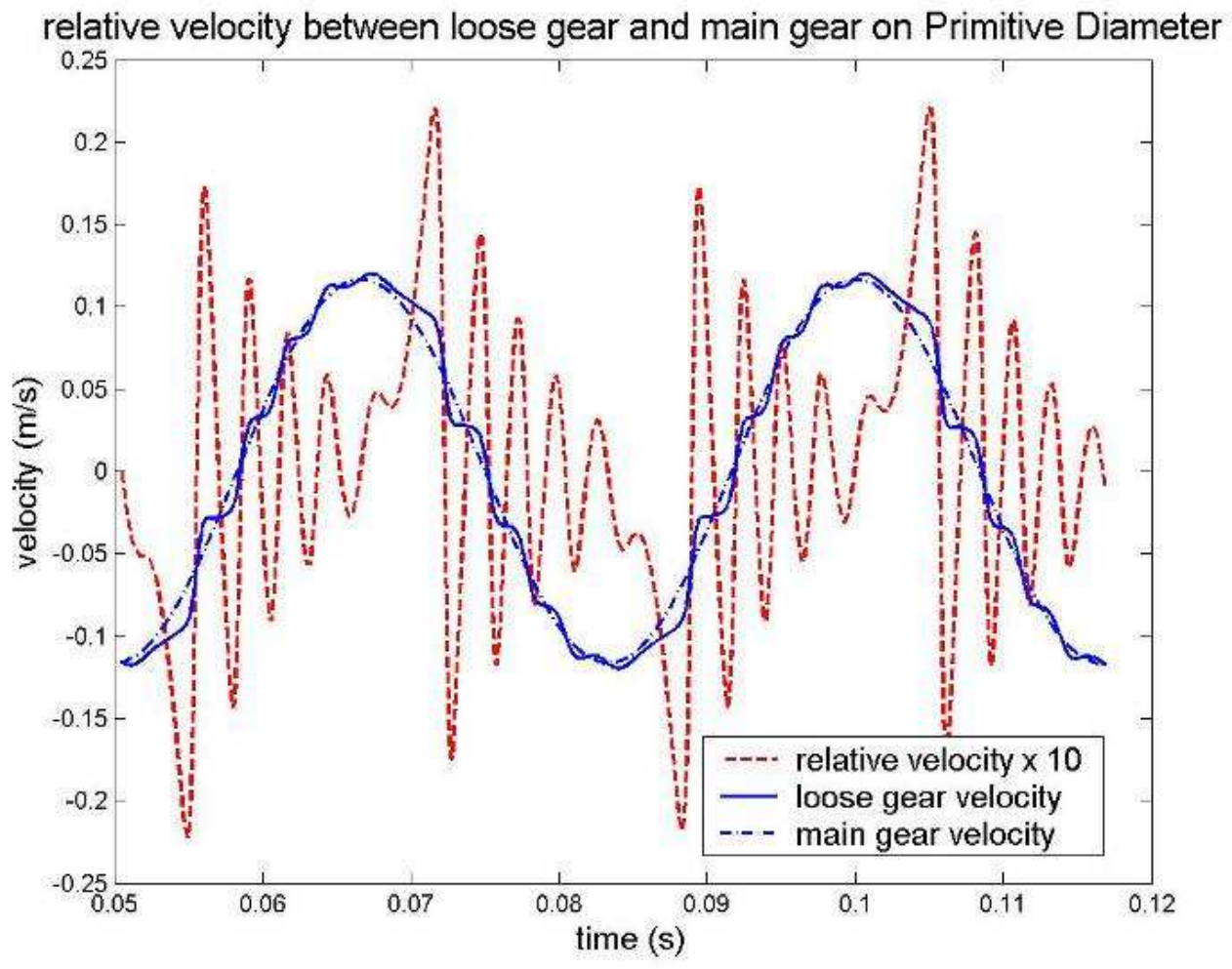

Fig .24. Relative velocity - Velocities for $30 \mathrm{~Hz}$ and $500 \mathrm{Rad} \mathrm{s}^{2}$ 
${ }_{732} \quad .1$ Schematic diagram of the experimental setup

${ }_{733} \quad .2$ Pictures of the experimental setup

$.3 \quad$ Schematic diagram of gear configuration

.5 Temporal signals for different levels of a $30 \mathrm{~Hz}$ excitation

.6 Evolution of shocks shape versus excitation level, for two different excitation frequencies. "Periodograms".

.7 Kinetical gear behaviour for a $30 \mathrm{~Hz}-500 \mathrm{rad} / \mathrm{s}^{2}$ excitation

.8 Evolution of loose gear acceleration spectral shape versus main shaft acceleration level

$.9 \quad$ Loose gear acceleration shape evolution according to excitation frequency

.10 Contact areas for several models

.11 Elastic Behaviour on pitch perimeter

.12 Schematic representations of gears in contact

.13 Parametric identification of rational damping based on experimental results

.14 Comparison between measurements and simulation - Displacements for $30 \mathrm{~Hz}$ and 300 $\operatorname{Rad} \mathrm{s}^{-2}$ 
.15 Comparison between measurements and simulation - Velocity for $30 \mathrm{~Hz}$ and $300 \mathrm{Rad} \mathrm{s}^{-2}$

.16 Comparison between measurements and simulation - Acceleration for $30 \mathrm{~Hz}$ and $300 \mathrm{Rad}$ $\mathrm{s}^{-2}$

.17 Relative displacement (instantaneous backlash) for $30 \mathrm{~Hz}$ and $300 \mathrm{Rad} \mathrm{s}^{-2}$

.18 Comparison between measurements and simulation - Acceleration for $60 \mathrm{~Hz}$ and 300 Rad.s ${ }^{-2}$

.19 Comparison between measurements and simulation - Relative displacement (instantaneous backlash) for $60 \mathrm{~Hz}$ and $300 \mathrm{Rad} \mathrm{s}^{-2}$

.20 Comparison between measurements and simulation - Velocity for $60 \mathrm{~Hz}$ and $300 \mathrm{Rad}^{2}$

.21 Comparison between measurements and simulation - Acceleration for $30 \mathrm{~Hz}$ and $500 \mathrm{Rad}$ $s^{2}$

.22 Comparison between measurements and simulation - Relative displacement (instantaneous backlash) for $30 \mathrm{~Hz}$ and $500 \mathrm{Rad} \mathrm{s}^{2}$

.23 Comparison between measurements and simulation - Velocity for $30 \mathrm{~Hz}$ and $500 \operatorname{Rad}^{2}$

.24 Relative velocity - Velocities for $30 \mathrm{~Hz}$ and 500 $\operatorname{Rad} s^{2}$ 